University of Nebraska - Lincoln

DigitalCommons@University of Nebraska - Lincoln

Agronomy \& Horticulture - Faculty Publications

Agronomy and Horticulture Department

2014

Switchgrass (Panicum virgatum $\mathrm{L}$ ) flag leaf transcriptomes reveal molecular signatures of leaf development, senescence, and mineral dynamics

\author{
Nathan A. Palmer \\ University of Nebraska-Lincoln, nathan.palmer@ars.usda.gov \\ Teresa Donze-Reiner \\ University of Nebraska-Lincoln, tdonze@wcupa.edu \\ David Horvath \\ Sunflower and Plant Biology Research Unit, USDA-ARS, Fargo, North Dakota, david.horvath@ars.usda.gov \\ Tiffany Heng-Moss \\ University of Nebraska-Lincoln, thengmoss2@unl.edu \\ Brian M. Waters \\ University of Nebraska-Lincoln, bwaters2@unl.edu
}

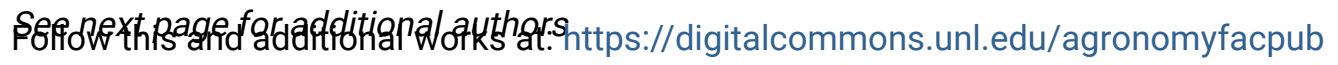

Part of the Agriculture Commons, Agronomy and Crop Sciences Commons, Botany Commons, Genetics Commons, and the Plant Biology Commons

Palmer, Nathan A.; Donze-Reiner, Teresa; Horvath, David; Heng-Moss, Tiffany; Waters, Brian M.; Tobias, Christian M.; and Sarath, Gautam, "Switchgrass (Panicum virgatum $\mathrm{L}$ ) flag leaf transcriptomes reveal molecular signatures of leaf development, senescence, and mineral dynamics" (2014). Agronomy \& Horticulture -- Faculty Publications. 728.

https://digitalcommons.unl.edu/agronomyfacpub/728

This Article is brought to you for free and open access by the Agronomy and Horticulture Department at DigitalCommons@University of Nebraska - Lincoln. It has been accepted for inclusion in Agronomy \& Horticulture -Faculty Publications by an authorized administrator of DigitalCommons@University of Nebraska - Lincoln. 


\section{Authors}

Nathan A. Palmer, Teresa Donze-Reiner, David Horvath, Tiffany Heng-Moss, Brian M. Waters, Christian M.

Tobias, and Gautam Sarath 


\title{
Switchgrass (Panicum virgatum L) flag leaf transcriptomes reveal molecular signatures of leaf development, senescence, and mineral dynamics
}

\author{
Nathan A. Palmer • Teresa Donze-Reiner • \\ David Horvath • Tiffany Heng-Moss • Brian Waters • \\ Christian Tobias • Gautam Sarath
}

Received: 16 April 2014 /Revised: 4 August 2014 / Accepted: 18 August 2014

(C) Springer-Verlag Berlin Heidelberg (outside the USA) 2014

\begin{abstract}
Switchgrass flag leaves can be expected to be a source of carbon to the plant, and its senescence is likely to impact the remobilization of nutrients from the shoots to the rhizomes. However, many genes have not been assigned a function in specific stages of leaf development. Here, we characterized gene expression in flag leaves over their development. By merging changes in leaf chlorophyll and the expression of genes for chlorophyll biosynthesis and degradation, a four-phase molecular roadmap for switchgrass flag leaf ontogeny was developed. Genes associated with early leaf development were up-regulated in phase 1. Phase 2 leaves had
\end{abstract}

Electronic supplementary material The online version of this article (doi:10.1007/s10142-014-0393-0) contains supplementary material, which is available to authorized users.

N. A. Palmer $\cdot$ G. Sarath

Grain, Forage and Bioenergy Research Unit, USDA-ARS, Lincoln, NE 68583-0937, USA

G. Sarath $(\bowtie)$

Grain, Forage and Bioenergy Research Unit, USDA-ARS, and

Department of Agronomy and Horticulture, University of Nebraska,

137 Keim Hall, Lincoln, NE 68583-0937, USA

e-mail: Gautam.Sarath@ars.usda.gov

T. Donze-Reiner $\cdot \mathrm{T}$. Heng-Moss

Department of Entomology, University of Nebraska, Lincoln,

NE 68583-0816, USA

D. Horvath

Sunflower and Plant Biology Research Unit, USDA-ARS, Fargo, ND 58102-2765, USA

B. Waters

Department of Agronomy and Horticulture, University of Nebraska, Lincoln, NE 68583-0915, USA

C. Tobias

Genomics and Gene Discovery Research Unit, USDA-ARS, Albany,

CA 94710, USA increased expression of genes for chlorophyll biosynthesis and those needed for full leaf function. Phase 3 coincided with the most active phase for leaf $\mathrm{C}$ and $\mathrm{N}$ assimilation. Phase 4 was associated with the onset of senescence, as observed by declining leaf chlorophyll content, a significant up-regulation in transcripts coding for enzymes involved with chlorophyll degradation, and in a large number of senescence-associated genes. Of considerable interest were switchgrass NAC transcription factors with significantly higher expression in senescing flag leaves. Two of these transcription factors were closely related to a wheat NAC gene that impacts mineral remobilization. The third switchgrass NAC factor was orthologous to an Arabidopsis gene with a known role in leaf senescence. Other genes coding for nitrogen and mineral utilization, including ureide, ammonium, nitrate, and molybdenum transporters, shared expression profiles that were significantly co-regulated with the expression profiles of the three NAC transcription factors. These data provide a good starting point to link shoot senescence to the onset of dormancy in field-grown switchgrass.

Keywords Flag leaves · Ontogeny · Panicum virgatum . RNA-seq $\cdot$ Senescence $\cdot$ Switchgrass $\cdot$ Transcriptomes . Biosample accession number: SRX481052

\section{Introduction}

Switchgrass (Panicum virgatum $\mathrm{L}$.) is a perennial $\mathrm{C}_{4}$ species that is likely to be grown as a source of biomass for the biofuel sector (Vogel et al. 2011). Perenniality resides in the belowground rhizome and crown tissues that are the primary sources of tiller buds. Dormant tiller buds elongate in spring to produce aboveground biomass. Each tiller consists of several phytomers, each comprised of nodes, internodes, and leaves 
(Moore and Moser 1995), and most tillers will become reproductive (Mitchell et al. 1997). The last leaf to be produced on a flowering tiller is the flag leaf, which subtends the inflorescence. Leaves are the dominant source of photosynthates. During a growing season, leaves go through several stages of development, with dynamic physiological and metabolic activities being reflected by underlying gene expression. An increased understanding of the coordination of gene expression and leaf development could lead to insights into the biology of switchgrass plants and lead to new breeding targets for crop improvement.

Flowering and seed production are generally accompanied by tiller senescence and associated with the onset of dormancy in the rhizomes. It is likely that flag leaves will supply nutrients to both the seeds and the rhizomes (sinks). Initiation of senescence in flag leaves could provide signals that trigger remobilization of nutrients from the shoots, and the initiation of dormancy mechanisms in the rhizomes, but these signals are unknown. Switchgrass can remobilize substantial amounts of $\mathrm{N}$ and other nutrients to the crowns and rhizomes, especially towards the end of a growing season (Wayman et al. 2013; Wilson et al. 2013; Yang et al. 2009). Improving remobilization of $\mathrm{N}$ and minerals from the aboveground biomass to the belowground tissues is important to switchgrass breeding programs, since biomass with lower $\mathrm{N}$ and minerals significantly improves sustainability of production and conversion of biomass to fuels in thermochemical platforms (Patwardhan et al. 2010; Sarath et al. 2014). We currently lack an understanding of the genes involved in regulating and carrying out nutrient remobilization during senescence, and improved knowledge of genes preferentially expressed in senescing tissues during leaf senescence could lead to new insights.

In cereal crops, flag leaves provide a large portion of the nutrients needed for grain fill (Biswal and Kohli 2013), and different aspects of flag leaf senescence have been studied in several major cereal crops (for example Derkx et al. 2012; Gregersen and Holm 2007; Kohl et al. 2012). In a large-scale transcriptomic analysis of the genes involved in maize internode and leaf senescence (Sekhon et al. 2012), a large number of pathways were common or different between these two tissues. Commonalities and differences in the progression of leaf senescence programs between maize and Arabidopsis (Sekhon et al. 2012) were uncovered by using a database of plant senescence-associated genes (SAGs) (Liu et al. 2011b). While these studies and others in the model dicot Arabidopsis ( $\mathrm{Li}$ et al. 2012; Rauf et al. 2013) have been productive in developing a framework to understand leaf senescence, they may not be reflective of all plant species, since differences exist between plant species, and especially between annuals and perennials (Davies and Gan 2012; Thomas 2013; Thomas et al. 2000).

In this study, we evaluated molecular changes accompanying leaf development and senescence through global transcriptional profiling in field-grown switchgrass plants. By computational analysis of expression of over 40,000 transcripts over developmental time, a number of key switchgrass genes and networks that impact leaf growth, development, senescence, and remobilization of nutrients have been found. This work could provide needed information about potential mechanisms that could integrate changes in flag leaf metabolism to the onset of dormancy in the rhizomes and provide molecular targets for phenotyping plants with improved traits (Sarath et al. 2014).

\section{Experimental methods}

Field layout, replication, and sample collection

Field plantings of cv Summer switchgrass were established in small $(1 \mathrm{~m} \times 1.2 \mathrm{~m})$ plots using seedlings raised in a greenhouse in June 2009 at the experimental farms of the University of Nebraska, near Mead, NE. Twelve plants were planted in each plot to mimic sward conditions at maturity. Switchgrass fields were not irrigated and managed as described elsewhere (Vogel and Mitchell 2008). There were 30 replicated small plots in this field. Flag leaves were harvested from plants during the 2012 growing season, at which time, plants were fully established, but individual plants could still be identified within each small plot. Plots and plants were randomly selected to capture maximum diversity at each harvest date. Three biological replicate pools of flag leaves harvested from ten separate plants each were collected at five different harvest dates (a total of 15 samples from $\sim 100$ individual plants) corresponding to different developmental states of the plant: July 3 ( $>90 \%$ headed), July 27 (>80\% anthesis), August 16 (>90\% seed set), August 31 (>70\% mature seed), and September 19 (>90\% senescence onset). Collected tissues were immediately flash-frozen with liquid nitrogen and stored at $-80{ }^{\circ} \mathrm{C}$. Leaf samples were later ground in a cryogenic grinder (Palmer et al. 2012) prior to analysis.

\section{Chlorophyll quantification}

Chlorophyll was extracted in $80 \%$ acetone in water and quantified using the method described by Porra et al. (1989).

\section{RNA extraction}

Total RNA was extracted from $100 \mathrm{mg}$ of frozen plant tissue using TRIzol reagent following manufacturer protocol (Invitrogen, Carlsbad, CA, USA). RNA was cleaned up and residual DNA was removed using the RNeasy MinElute Cleanup Kit (Qiagen, Valencia, CA, USA). 
RNA sequencing

One microgram of total RNA was reverse-transcribed and converted to sequencing libraries using the TruSeq RNAseq Library kit per manufacturer's suggestion (Illumina Inc, San Diego, CA). Utilizing unique indexes from the library kit, individual samples were diluted and to a concentration of $10 \mathrm{nM}$ and multiplexed at five samples per lane. Single read 100-bp sequencing was performed on the Illumina HiSeq2000 system. Following sequencing, fastq files were used for mapping.

\section{Mapping and expression counting}

HiSeq2000 100-bp reads (an average of 45 million reads/ sample) were mapped to the switchgrass draft genome (Pvi0, www.phytozome.org (Goodstein et al. 2012)) using Bowtie2 (Langmead and Salzberg 2012) with "sensitive-local" settings. On average, $93 \%$ of the reads mapped to the draft genome with $78 \%$ of the reads mapping to annotated gene regions. Gene counts were calculated using the primary transcript annotation file released with Pvi0 and the program featureCounts (Liao et al. 2013).

\section{Differential expression analysis}

Prior to differential expression testing, genes that did not have an average expression level of 50 counts in at least one time point were removed from the dataset. This was an arbitrary cutoff, approximately equivalent to 1 read per million, and used to minimize the potential for overestimating differences between harvest dates arising from genes with low expression. Differential expression analysis was done using DESeq2 (Anders and Huber 2010) in R (Team 2011). Pairwise comparisons of all five timepoints (ten total comparisons) were carried out to generate a list of differentially expressed genes (DEGs) for the entire dataset using an FDR cutoff of 0.05.

\section{Gene set creation}

Metabolic pathways for the switchgrass draft genome were built based on existing pathways found in the Kyote Encyclopedia of Genes and Genomes (KEGG) (Kanehisa et al. 2012; Kanehisa et al. 2014). Sorghum proteins annotated at each node in pathways of interest were used to find the best switchgrass matches using blastp (Altschul et al. 1990). Genes involved in histone (de)methylation and (de)acetylation were identified following the approach used by Cigliano et al. (2013) using already identified chromatin modification genes annotated in ChromDB (www.chromdb.org). Nutrient transporters in the switchgrass draft genome were identified as previously described (Palmer et al. 2014).
Transcription factors were identified based on PFAM annotations included with the draft genome release and the rules for classification of Transcription Factor Families as detailed in the Plant Transcription Factor Database v3.0 (plntfdb.bio.uni-potsdam.de/v3.0) (Perez-Rodriguez et al. 2010).

Previously identified SAGs from Arabidopsis (Li et al. 2012; Liu et al. 2011b) and rice (Liu et al. 2008) were used to identify putative SAGs in switchgrass. Orthologs were identified in the switchgrass draft genome by matching the closest Arabidopsis and rice genes included with the genome annotation with the above SAG lists. The switchgrass orthologs were then filtered for genes differentially expressed with peak expression in the fourth or fifth collection time point to yield a set of putative switchgrass SAGs.

Pathway studios analysis

Log2-transformed expression data was used in the program Pathway Studio 9.0 (Nikitin et al. 2003) to identify overrepresented ontologies. To facilitate this analysis, switchgrass sequences were mapped to the most similar Arabidopsis gene using BlastX, and the resulting gene function associations were used for gene set and subnetwork analysis using default settings.

\section{Statistical analysis}

Principal component analysis (PCA) was done using the "prcomp" function in R (Team 2011). Heatmaps were created by hierarchical clustering in JMP ${ }^{\circledR}$ Version 9.0 (SAS Institute Inc, Cary, NC, 1989-2007) using Ward's method on standardized gene expression values.

\section{Results}

Changes in gene expression define developmental stages

On average, approximately $45.6 \mathrm{M}$ reads were obtained for each sample, of which almost $93 \%$ could be mapped to the switchgrass genome version 0.0 available at www.phytozome. org (Goodstein et al. 2012) and over $78 \%$ were mapped to specific genes (Table S1). An analysis of all unique transcripts with average normalized read counts $>50$ in at least one harvest date is shown (Fig. 1a). Of these genes, 27,214 were common to all datasets, and only a small fraction $(<0.04 \%)$ were uniquely associated with a specific harvest date. Numbers of shared genes were fewer between more distant harvest dates (Fig. 1a), suggesting that underlying changes in leaf physiology were responsible for the changing expression profiles. 

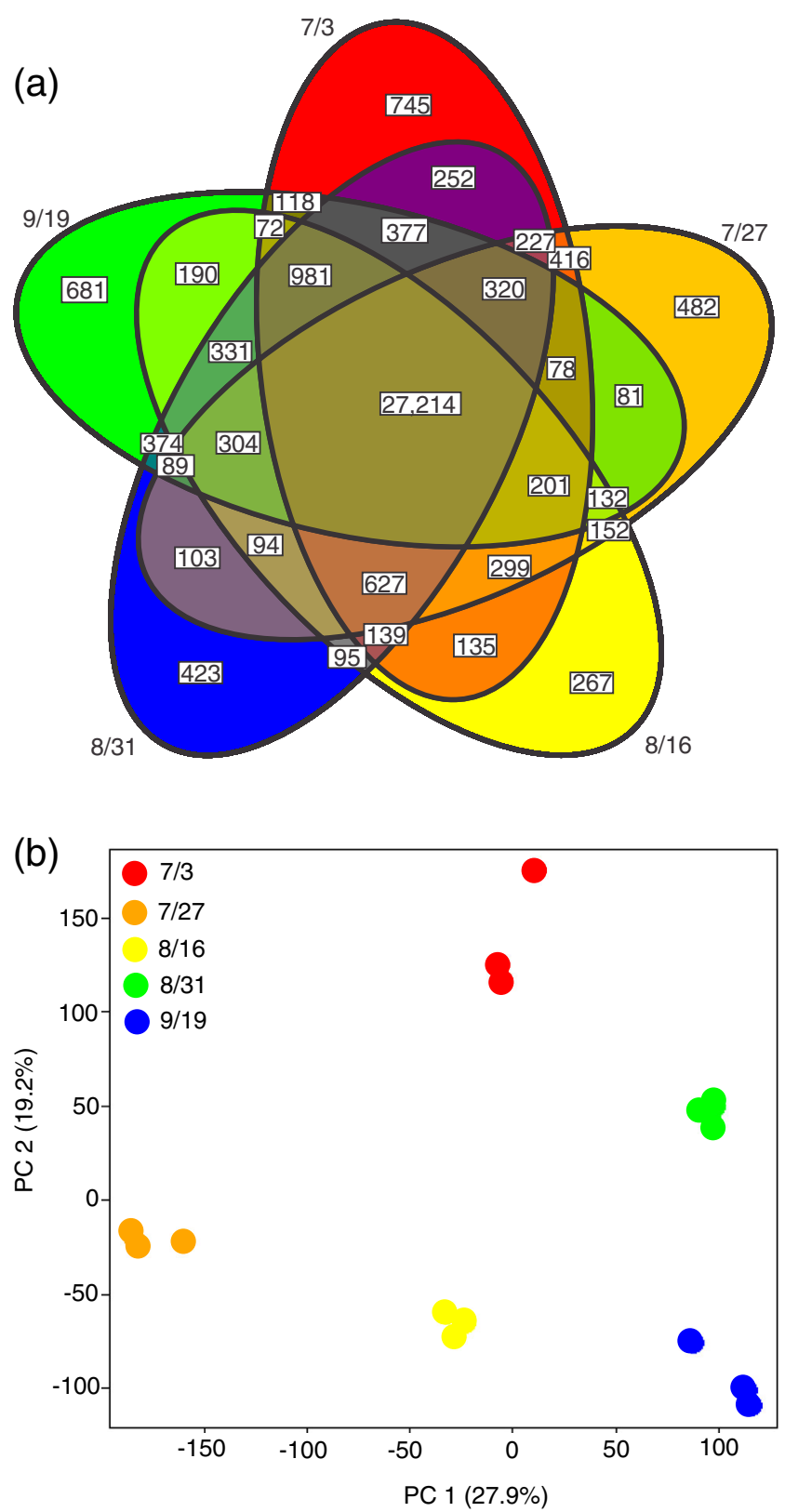

Fig. 1 Gene expression profiles differentiate flag leaf transcriptomes. a Venn diagram of gene expression at different harvest dates. b PCA of transcriptomic dataset

We next asked whether transcriptomes at each harvest date could be used as molecular signatures of the stage of development. At each harvest date, the transcriptomes were effectively separated by PCA (Fig. 1b), suggesting that these differences arose from underlying developmental status and to some extent from environmental conditions associated with the time of harvest (supplementary Fig. S1). The first component accounted for $27.9 \%$ of the variation and separated the transcriptomes from the anthesis $(7 / 27)$, early seed fill $(8 / 16)$, and physiological maturity (9/19) harvest dates. PC2 accounted for $19.2 \%$ of the variation and separated the transcriptomes present in flag leaves harvested at the heading
$(7 / 3)$ and late seed fill stage (8/31) of plant development. Within each harvest date, the greatest variation between the biological replicates was observed in the transcriptomes for the earliest (7/3) and last (9/19) harvest, plausibly attributable to variation in plant development within switchgrass populations (Bartley et al. 2013).

Chlorophyll levels in switchgrass flag leaves were low at the first harvest, increased to a maximum near the early seedset stage, and declined thereafter, with the lowest chlorophyll levels at the last harvest date (Fig. 2a). In general, transcript abundance for the six gene families coding for proteins involved in chlorophyll biosynthesis was highest in flag leaves harvested at anthesis (7/27) and least abundant in senescing leaves harvested in September (9/19). In contrast, three gene families coding for switchgrass protein orthologs involved in chlorophyll catabolism were strongly up-regulated at the last harvest date (Fig. 2b). The loss of chlorophylls in flag leaves harvested at this date combined with the gene expression data indicated that senescence had been initiated in these plants sometime after seed filling had started.

Combining the information shown in Fig. 2a, b, we developed a roadmap of switchgrass flag leaf development to assist in interpreting the large transcriptomic datasets. Essentially, phase 1 (light green bar, Fig. 2c) was associated with leaf expansion. Phase 2 (dark green bar, Fig. 2c) was associated with a substantial up-regulation of the genes associated with chlorophyll biosynthesis (blue line, Fig. 2c), likely coinciding with the maturation of the flag leaves from sinks to sources. Phase 3 (yellow bar, Fig. 2c) was associated with a decline in transcript abundances for the genes associated with chlorophyll biosynthesis and a small increase in the transcripts of genes associated with chlorophyll degradation. Phase 4 (brown bar, Fig. 2c) was associated with a large increase in transcripts coding for proteins involved in chlorophyll degradation, consistent with the onset of leaf senescence.

$\mathrm{C}$ and $\mathrm{N}$ assimilation genes are substantially up-regulated in phase 2

Expression of genes coding for proteins associated with the $\mathrm{C}_{4}$ pathway and $\mathrm{CO}_{2}$ and $\mathrm{N}$ assimilation were analyzed to determine if they followed the phases outlined in Fig. 2c. Mapped reads for individual genes within a gene family annotated as coding for the same protein were tabulated, and counts for all the genes within a given gene family were totaled and used to generate color heat maps (Fig. 3). These data are separate from the DEG analyses discussed later in the text.

Genes linked to $\mathrm{C}_{4}$ photosynthesis were all highly expressed at phase 2 (Fig. 3a), except for phosphoenolpyruvate carboxylase kinase genes (PEPCk) which codes for a kinase that modulates phosphoenolpyruvate carboxylase (PEPC) activities through phosphorylation (Chollet et al. 1996). However, all of these genes were down-regulated in leaves at 
(a)

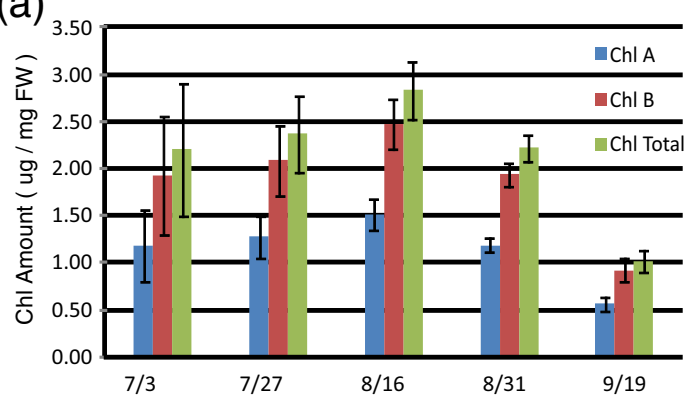

(b)

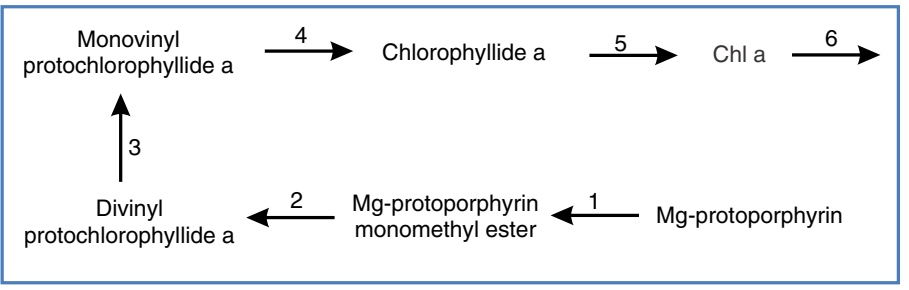

Chlorophyll Biosynthesis

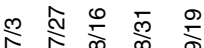

1 Protoporphyrin methyltransferase

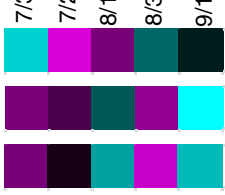

3

Protoporphyrin cyclase

8-vinyl reductase

4 Protochlorophyllide oxidoreductase

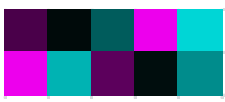

5

Chlorophyll synthetase

6

Chlorphyll a oxygenase

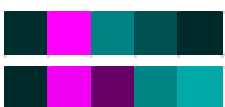

Fig. 2 Road map of switchgrass flag leaf development. a Total leaf chlorophyll content. b Expression profiles of genes coding for proteins involved in chlorophyll biosynthesis and degradation. Overview of chlorophyll biosynthesis (blue box) and chlorophyll degradation (red box). Z score heatmap of relative total expression. Cyan is low expression,

successive harvests. This pattern of $\mathrm{C}_{4}$-related gene expression in switchgrass flag leaves suggests that phase 3 is one where leaves are fully mature and functioning efficiently as sources for fixed C. Genes involved in the $\mathrm{C}$ assimilatory pathway (Fig. 3b) and in $\mathrm{N}$ metabolism (Fig. 3c) appeared to be regulated similarly to genes associated with $\mathrm{CO}_{2}$ assimilation, consistent with the developmental patterns suggested above. An exception was NADH-DEPENDENT GLUTAMATE DEHYDROGENASE (GDHb, Fig. 3c) for which transcript abundance was highest in senescing flag leaves.

Genes associated with ascorbate and glutathione metabolism are differentially regulated

Expression of genes involved with ascorbate biosynthesis (Linster and Clarke 2008) was generally greatest during
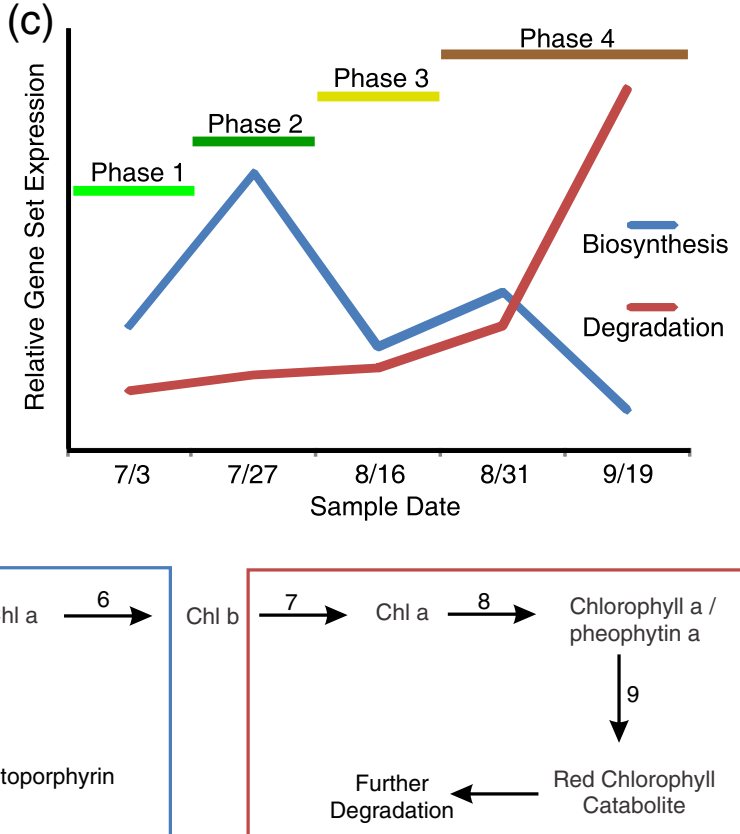

Chlorophyll Degradation
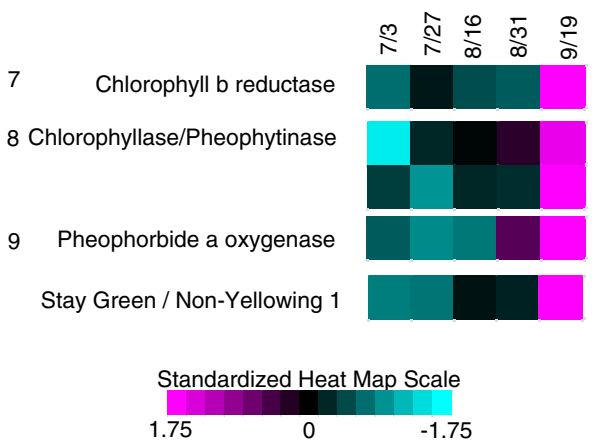

magenta is high expression. c Road map of flag leaf development categorized in four phases based on data shown in panels a and $\mathbf{b}$. Blue line $=$ chlorophyll biosynthesis; brown line $=$ chlorophyll degradation . The identities of each gene family shown in this figure are given in supplementary Excel file 1

phases 2 and 3 (Fig. 3d) and appears to be linked with the period of growth and function as a carbon source. There was, however, an increase in the abundance of transcripts coding ascorbate peroxidases $(A s c P r x)$ at later harvests. In contrast, transcripts coding for monodehydroascorbate reductase (mDHAR) had a bimodal expression profile coincident with phase 2 and phase 4 stages. Transcripts for genes coding for dehydroascorbate reductase (DHAR) were relatively constant over the first four harvests, before declining in senescing leaves.

Glutathione is another important redox intermediate in cells and serves multiple roles during plant development (Gill and Tuteja 2010). Transcripts for genes coding for glutathione biosynthesis were up-regulated at the phases 2 and 4 (Fig. 3d). Genes coding for enzymes related to glutathione catabolism were most abundantly expressed during phase 4 (Fig. 3d). 
Fig. 3 Changes in the expression profiles of genes coding for enzymes involved in key functions in switchgrass flag leaves. a $\mathrm{C}_{4}$ pathway. b Calvin cycle. $\mathbf{c}$ Nitrogen assimilation. $\mathbf{d}$ Ascorbate and glutathione metabolism. Cyan is low expression, magenta is high expression. The identities of each gene family shown in this figure are given in supplementary Excel file 1
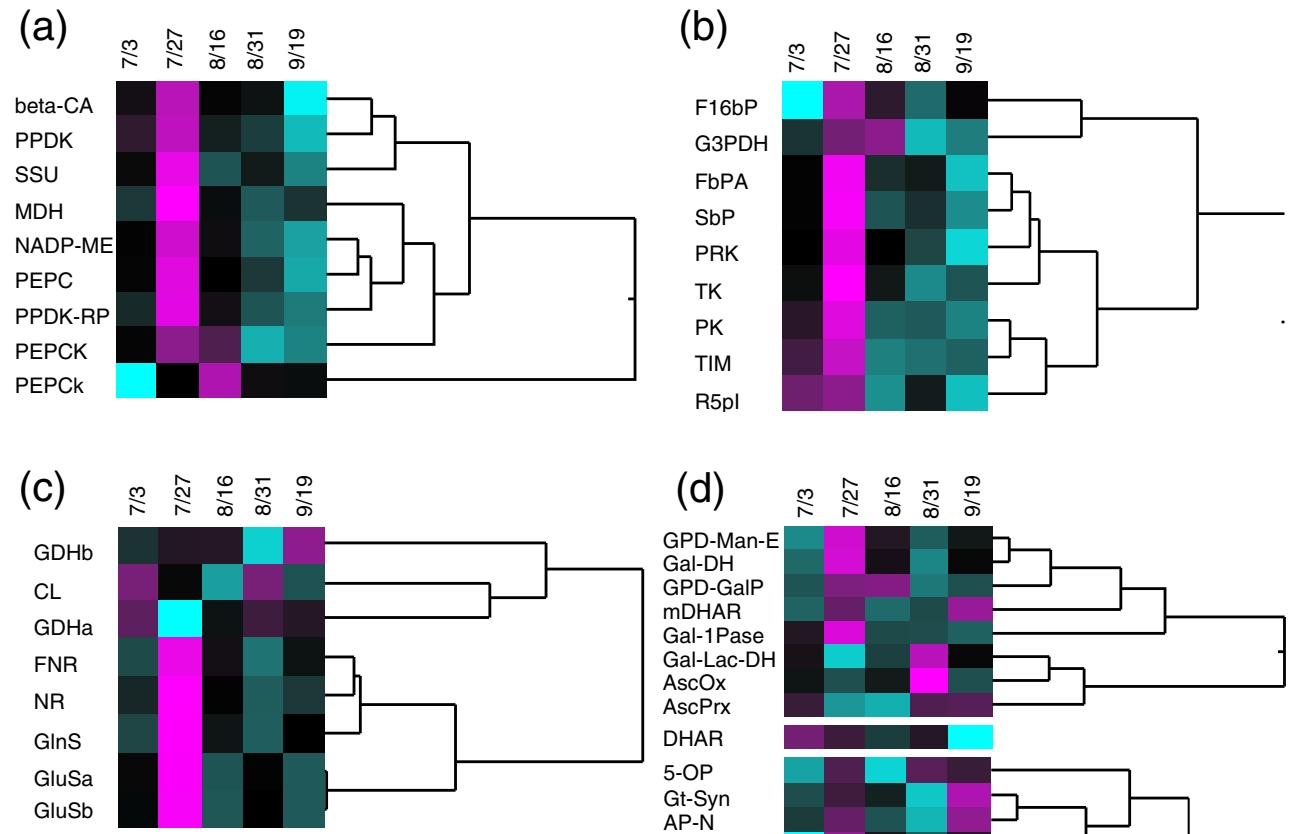

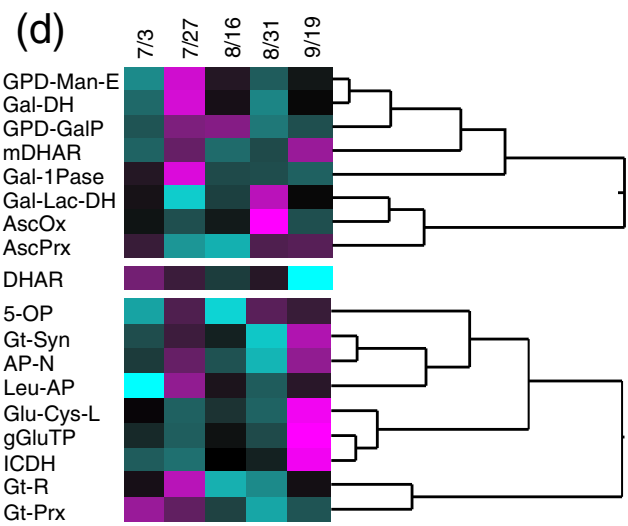

Gene set enrichment analysis identifies possible regulatory factors controlling leaf development

Gene set enrichment analysis was performed sequentially for all pairwise comparisons (supplemental Table S2). Physiological processes involved in flavonoid biosynthesis (Kaempferol glucoside biosynthesis and Quercetin glucoside biosynthesis), cytokinin biosynthesis, and sequence-specific DNA binding transcription factor activity were preferentially expressed in the early developmental stages, while oxidative stress-associated ontologies (heme binding, oxygen binding, and monooxygenase activity) were preferentially expressed at later developmental stages. Several ontologies associated with the earlier time points (heme binding, oxygen binding, and monooxygenase activity) showed a reversal of expression patterns when the late August time point was compared to the final harvest supporting data shown in Figs. 2 and 3.

Subnetwork analysis generally indicated an increase in jasmonic acid signaling during senescence. There was also some indication that targets of auxin transport had a higher expression prior to senescence. Genes for proteins that regulate phosphate import were preferentially expressed during senescence, suggesting that remobilization of phosphate was occurring (see Supplementary file 2).

Among the more interesting associations observed in the subnetwork analysis was a strong differential expression of targets for miRNA156 (down-regulated during senescence) and miRNA164 (up-regulated during senescence as early as late August) (see Supplementary file 2).
Clustering of differentially expressed genes support developmental timeline of flag leaves

A two-way hierarchical clustering of all DEGs from the entire transcriptome dataset with an FDR $<0.05$ is shown in Fig. 4. The three biological replicates at each harvest date were quite similar in gene expression profiles and clustered together, consistent with the overall PCA analyses. The samples from the second sampling date form an outlier in both the PCA and differential hierarchal clustering analysis. It is noteworthy that this sampling date occurred shortly after the only significant rainfall of the season (Fig. S1). Indeed, many of the DEGs in this sample were indicative of a relaxed drought stress response, including higher expression of genes with ontologies associated with photosynthesis and carbon metabolism, along with lower expression of ABA-associated genes (Table S2)

Seven major clusters of significantly up-regulated genes were found across all harvest dates. Of these, one cluster of $\sim 1,619$ genes (cluster 4) had a distinct bimodal expression profile. These genes were specifically up-regulated in flag leaves at anthesis (7/27) and at physiological maturity (9/19). However, it is impossible to determine if these differences were related specifically to the developmental state of these plants or to the precipitation event just prior to harvest (Fig. S1). Many of the genes associated with clusters 1 and 3 code for proteins involved with growth and biosynthetic processes and have been described earlier (phases 1 and 2; Figs. 2 and 3). Cluster 2 genes (phase 3) were significantly upregulated at the third harvest time and appear to have been 


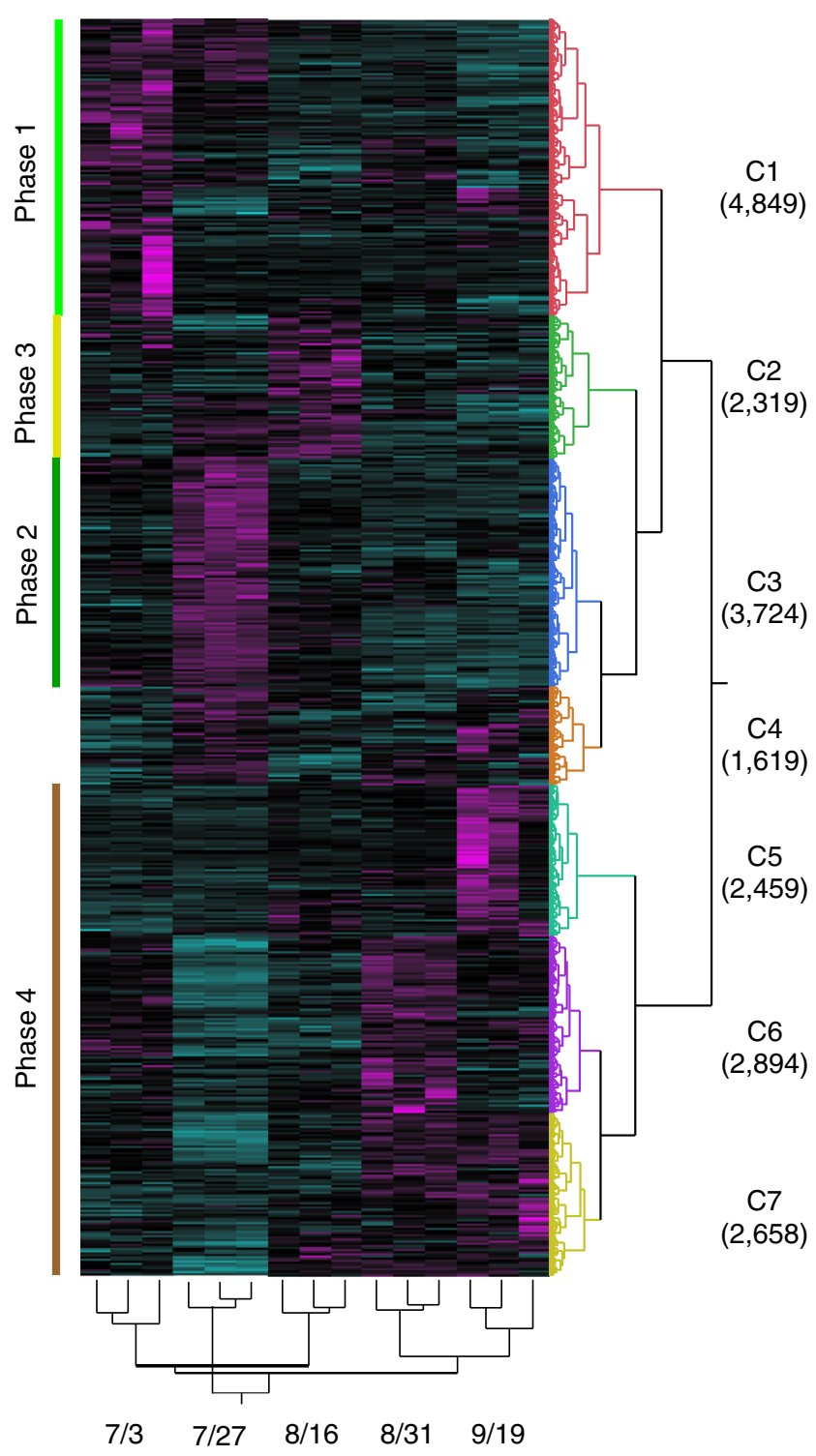

Fig. 4 Two-way clustering of differentially expressed genes (DEGs) across all harvested samples. At each harvest date, three biological replicates were analyzed. The bars on the left show the phases that were categorized in Fig. 2c. Seven major clusters labeled C1-C7 are so indicated. The numbers of DEGs within each cluster are in brackets. Cyan is low expression, majenta is high expression. The identity of each gene is provided in supplementary Excel file 1

in response to environmental conditions. There was no major precipitation event between the second and third harvest dates (Fig. S1), and this cluster contained several heat shock protein orthologs, suggesting that leaves were stressed. The remaining clusters were associated with senescence (clusters 4, 5, 6, 7, phase 4).

We next undertook a deeper analysis of DEGs that could be ascribed to specific functions. Expression heatmaps of genes coding for glutathione- $S$-transferases, transcription factors, transporters, and proteases that belong to large multigenic families are shown in supplementary Figs. S2-S5.
Expression profiles of several other classes of genes including the $S A G S$ are discussed below.

Genes involved in epigenetic regulation were differentially expressed between sampling dates

Reversible histone modification is a critical component of the epigenetic control of cellular process, and plant genomes contain an extensive set of genes that code for these enzymes. Well-characterized histone marks include acetylation and methylation among many others (Berr et al. 2011). Several genes coding for proteins classified as histone acetyltransferases (HAT, HAC, and HAG-Fig. 5a) (Cigliano et al. 2013) were found to be differentially expressed; however, their relative transcript abundances were variable and in general low. In contrast, the genes categorized as coding for histone deacetylases (HDA, SRT; Fig. 5a) were generally abundant during phase 2 and during leaf senescence (phase 4). One paralog, HDA8 (Pavirv00041899), was abundantly expressed in senescent leaves (Fig. 5a).

Many arginine-methyl transferases (PRMT) and SETdomain group lysine methyltransferase genes were found to be differentially expressed (Fig. 5b). Interestingly, four histone demethylases belonging to the Jumonji family of demethylases ( $\mathrm{Lu}$ et al. 2011) (JMJ-Fig. 5b), with high transcript abundance, were expressed at early or late periods of flag leaf development. Several genes paralogous to the ones shown in Fig. 5 had high abundance across all harvest dates (Table S3), suggesting that these genes were needed to maintain proper cellular functions. The relative contributions of individual genes to transcriptional events at specific loci are not known.

Transport processes are enhanced during senescence

A large number of mineral transporters were differentially expressed during switchgrass flag leaf development (Fig. 6; S4). In general, two distinct profiles of expression were observed: genes that were most abundant during the period of leaf expansion and transition to a source (phase 2), and genes that were most abundant during senescence (phase 4). Since both expansion and senescence stages of leaf development are likely to require transporters to mobilize minerals into (phase 2) or out of the leaf (phase 4), such a profile of transporter gene expression was anticipated.

Transcripts for a Si transporter were most abundant during active leaf metabolism and decreased when leaves transitioned into senescence (LSil, Fig. 6a), in a manner similar to that observed for a switchgrass crown and rhizome dataset (Palmer et al. 2014). Putative genes coding for ammonia (AMT) and nitrate (NRT) transporters with highest overall total transcript abundance were up-regulated during phase 2 in flag leaves (AMT1, NRT1, NRT2, and NRT3; Fig. 6a). However AMT3 

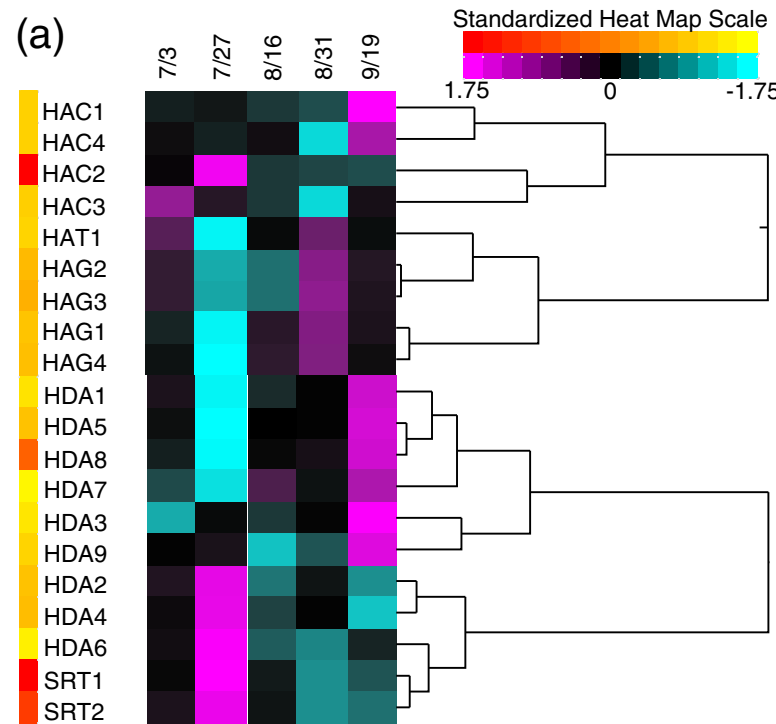

(b)

PRMT1
SGD16

SGD1

SGD2

SGD18

PRMT2

PRMT8

PRMT3

PRMT9

SGD13

SGD14

SGD23

SGD15

SGD22

PRMT4

SGD5

SGD4

SGD11

PRMT5

SGD12

PRMT6

PRMT7

SGD3

SGD10

SGD21

SGD7

SGD25

SGD17

SGD24

SGD19

SGD6

SGD20

SGD8

SGD9

HDMA1

HDMA2

HDMA4

JMJ8

JMJ9

HDMA3

JMJ10

JMJ1

JMJ3

JMJ2

JMJ4

JMJ5

JMJ6

JMJ7

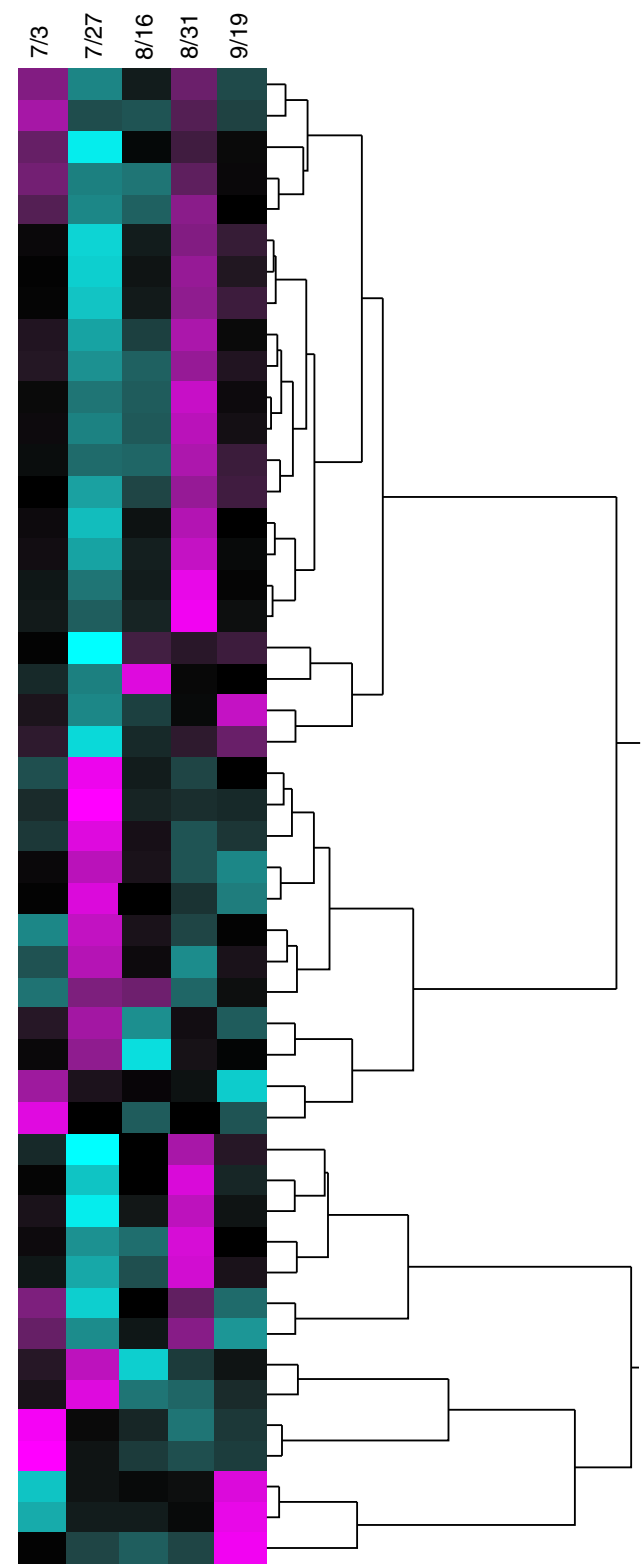

Fig. 5 Clustering of DEGs associated with histone modification. a Switchgrass genes coding for enzymes involved in histone acetylation and deacetylation. b Switchgrass genes coding for enzymes involved in histone methylation and demethylation. The relative expression value (number of mapped reads within each class across all time points) is shown as a single bar on the left (yellow is low counts, red is high counts). The overall expression across harvest dates are shown as colored rectangles. Cyan is no/low expression, magenta is high expression. The identity of each gene is provided in supplementary Excel file 1

and $A M T 4$, and NRT4, NRT5, NRT6, NRT10, and NRT12 were up-regulated during phase 4 . Transcripts for NRT1, NRT2, NRT3, and NRT13 were high during phase 2, whereas, transcripts for NRT12 were most abundant in senescing leaves (Fig. 6a).

Transcripts for nine genes encoding switchgrass potassium transporters (Palmer et al. 2014; labeled KUP; Fig. 6a) were present in the DEGs. Of these, three were most abundantly expressed during phase 2 of flag leaf development. Reads for the other six genes were most elevated in senescing leaves. Similar patterns were observed for the sulfur transporters (SULTR, Fig. 6a).

Four genes classified as sucrose transporters (SUT, Fig. 6a) were part of the DEGs and were highly expressed during phase 2 of switchgrass flag leaf development. Expression profiles of the SUTS were consistent with the substantial upregulation observed for a number of other biosynthetic genes regulating photosynthesis, and carbon and nitrogen assimilation observed during phase 2 as has been described earlier (see Figs. 2, 3, and 4). Three MOT genes (molybendum transporters) (Palmer et al. 2014) were most abundantly expressed during phase 4 (Fig. 6b).

We also analyzed the putative phosphate transporters ( $\mathrm{PHO}$ and PHT) and zinc/divalent metal transporters (ZIPs) (Liu et al. 2011a; Sinclair and Kramer 2012) (Fig. 6b). Four PHOs were most abundant during phase 1 , and the gene PHO3, which was most abundant, was highly expressed at phase 2 of flag leaf development. Inorganic phosphate requirements are expected to be high during leaf maturation and subsequent transition into a source leaf. Most of the PHT genes with high expression (red/orange boxes; Fig. 6b) were most abundant during phase 2 or phase 3 of flag leaf development where leaf biosynthetic activities appear to peak. Several other genes with lower expression (yellow; Fig. 6b) were significantly more abundant in senescing leaves, suggesting a role in phosphate remobilization (also see GSEA data, Table S2). Eight ZIP genes were found to be differently expressed during switchgrass flag leaf development (Fig. 6b)

Senescence and growth process are differential through seasonal development

Leaf senescence is accompanied by the increase in transcript abundances for a host of genes that are referred to as $S A G S$ 
(a)

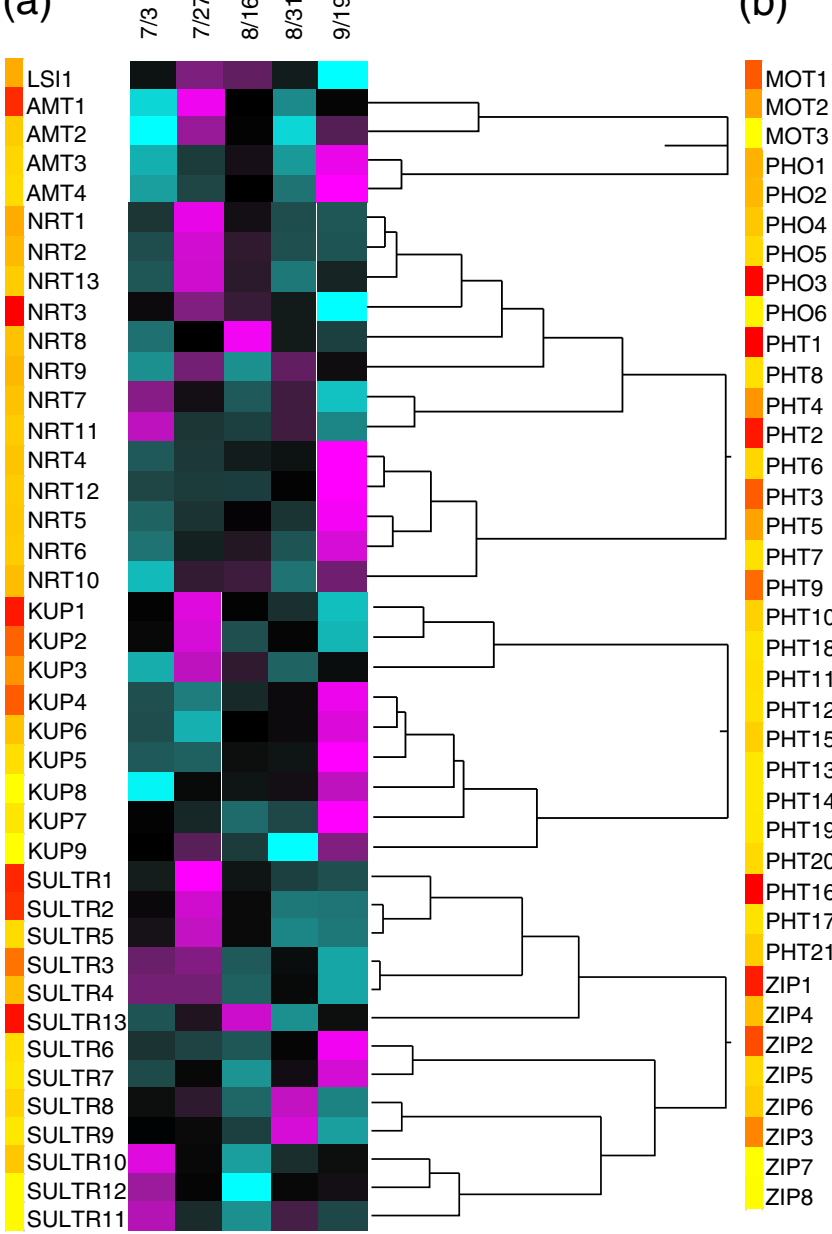

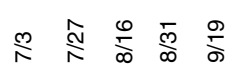

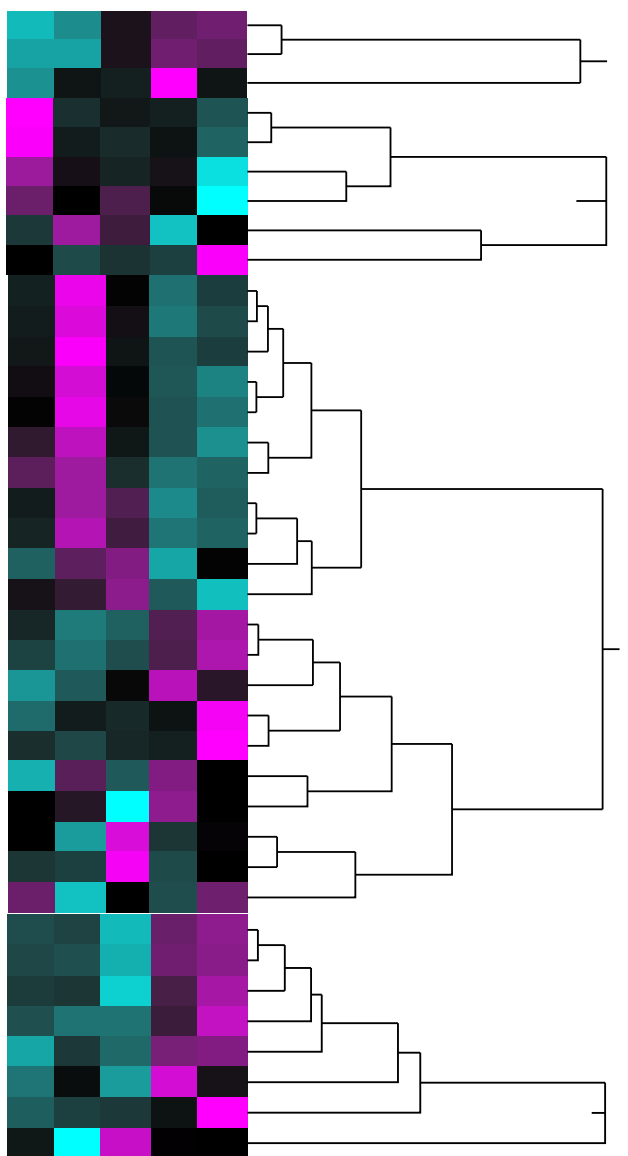

Fig. 6 Two-way clustering of DEGs belonging to different nutrient transporter classes across harvest dates. a Silicon, ammonia, nitrate, potassium, sulfate, and sugar transporters. b Molybdenum, phosphate, and zinc/copper/iron transporters. Other details are as described for Fig. 5

(Gepstein et al. 2003; Liu et al. 2011b). A large number of putative switchgrass $S A G S$ were significantly up-regulated at the last harvest date (Fig. 7), although smaller clusters were more abundantly expressed at earlier time points. As an example, transcripts of switchgrass AUXIN RESPONSE FACTOR 2 (ARF2) (Lim et al. 2010) orthologs SAGs 29, 47, and 55 (Fig. 7) were higher at the third harvest and either declined (SAG47 and SAG55) or increased with time (SAG 29; Fig. 7). A small cohort of genes provisionally identified as $S A G s$ were first up-regulated in flag leaves harvested at the early seed development stage (8/16; Fig. 7), which coincided with maximal leaf chlorophyll content (see Fig. 2).

Organic acids: the carbon currency from the breakdown of lipids during senescence

Breakdown of fatty acids via the $\beta$-oxidation pathway is one of the important processes that occurs in senescent tissues to recapture carbon (Troncoso-Ponce et al. 2013; Yang and Ohlrogge 2009). Genes associated with the $\beta$-oxidation and related pathways were significantly up-regulated during phase
4 (Fig. 8). We found 230 genes annotated as lipases that were differentially expressed, of which 88 had maximal expression during phase 4 (Fig. S6).

In contrast to Arabidopsis, transcripts for all of the genes needed for a functional glyoxylate cycle were strongly upregulated in senescing switchgrass leaves (Fig. 8, orange). The two key glyoxylate cycle enzymes, isocitrate lyase (ICL) and malate synthase (MS) (Chen et al. 2000a, b; Troncoso-Ponce et al. 2013), were found in greatest abundance in senescing (phase 4) flag leaves (Fig. 8). Conversion of fatty acids into organic acids requires reactions in glyoxysomes, cytoplasm, and mitochondria (Fig. 8). To a large extent, transcripts coding for all of the key enzymes localized in the different cellular compartments were significantly more abundant during phase 4 (Fig. 8).

Roles for switchgrass NAC transcription factors in remobilization

DEG analysis of several different classes of transcription factors are shown in Fig. S3 and for all the NAC genes in 


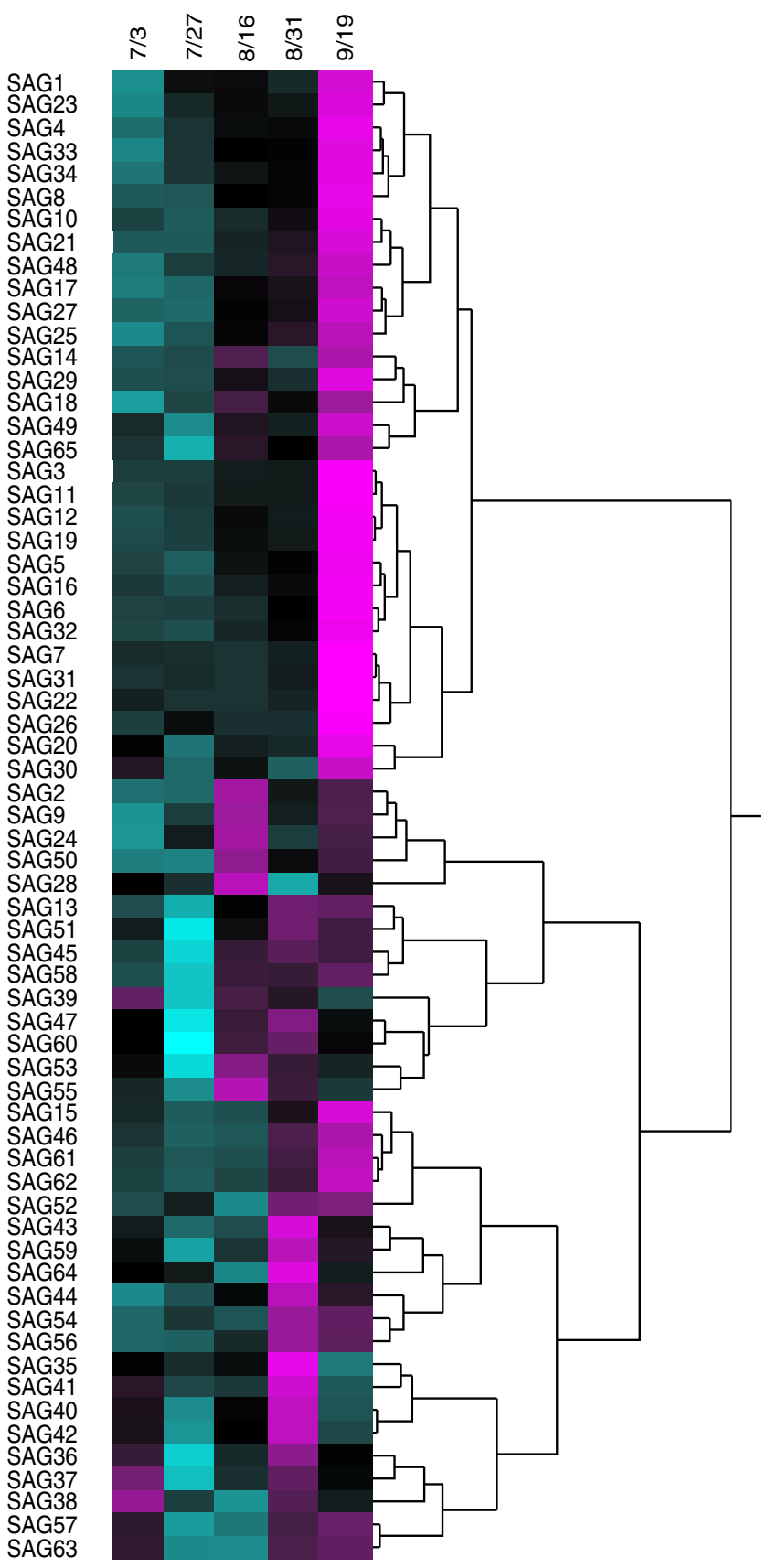

Fig. 7 Clustering of differentially expressed switchgrass SAGs. Cyan is low expression, majenta is high expression. The identities of each gene family shown in this figure are given in supplementary Excel file 1

Fig. S7. NAC transcription factors are members of a large family of related genes and proteins involved in virtually every aspect of plant development (Puranik et al. 2012). We found a total of 78 NACs in the DEGs (Fig. S7), of which 26 were most abundantly expressed at phase 1,6 at phase 2,2 at phase 3 , and 39 at phase 4 .

Using the wheat NAM-B1 protein sequence (Waters et al. 2009), orthologous proteins were identified in switchgrass, sorghum, foxtail millet, maize, Brachypodium, rice, and
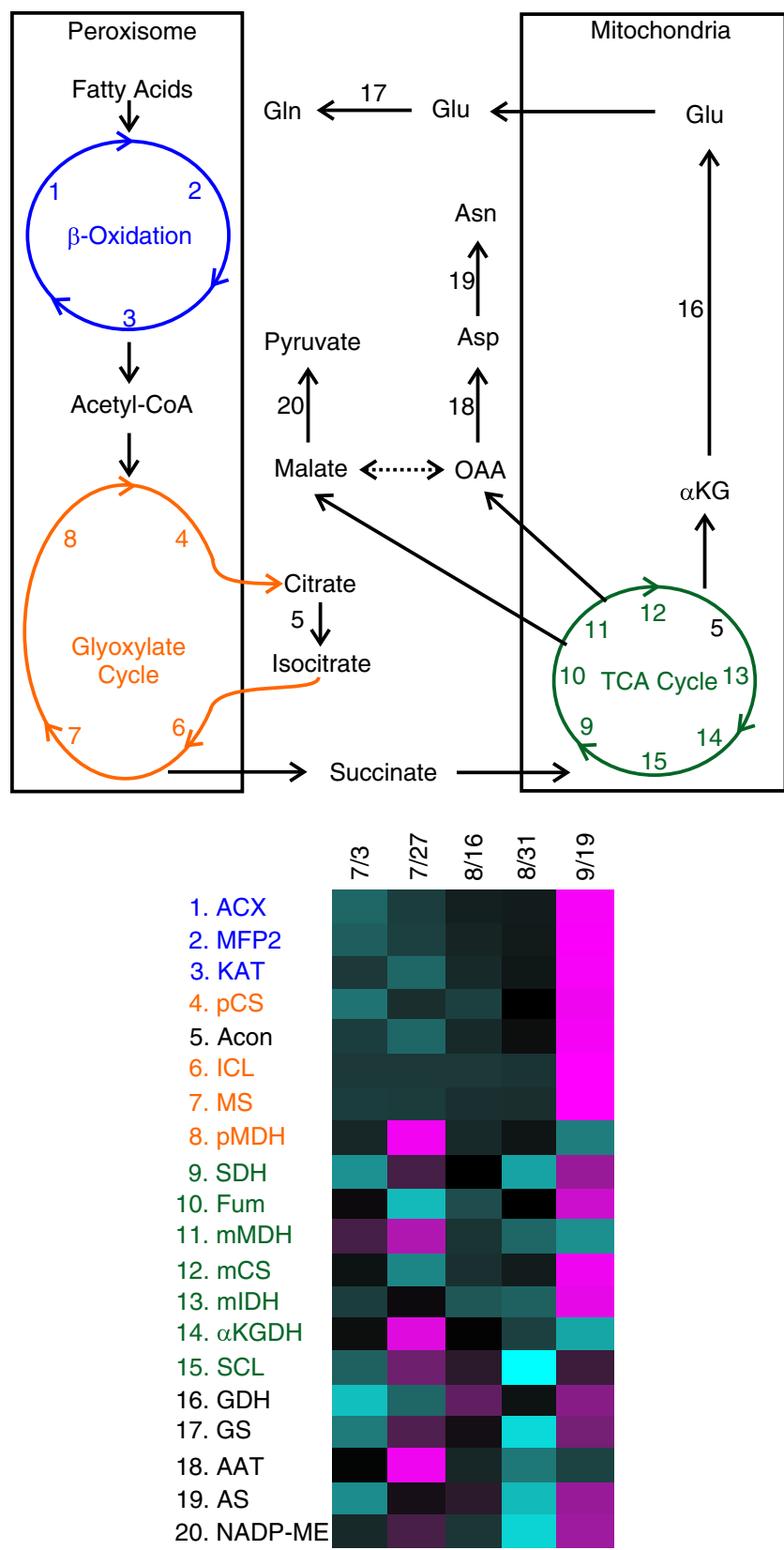

Fig. 8 Lipids are targeted to the $\beta$-oxidation pathway in senescing flag leaves. A simplified pathway linking the different compartments involved in this process is shown. Expression levels of each enzyme (1-11) identified in the pathways are shown as a color map. Cyan is low expression, magenta is high expression. Identity of each ortholog is provided in supplementary Excel file 1

Arabidopsis (Fig. 9a). The amino acid sequence near the Cterminus within the red box (Fig. 9a) distinguishes NAM-B1 from other related NACs. Close orthologs were identified in all the grasses but not in Arabidopsis. For switchgrass, only two NACs contained this specific domain (Pavirv00068192 and Pavirv00065253); however, a third closely related NAC did not have this specific sequence of amino acids (Pavirv00018572). A dendrogram of all these protein sequences (Fig. 9b) suggests that the Arabidopsis NAC025 
(a)

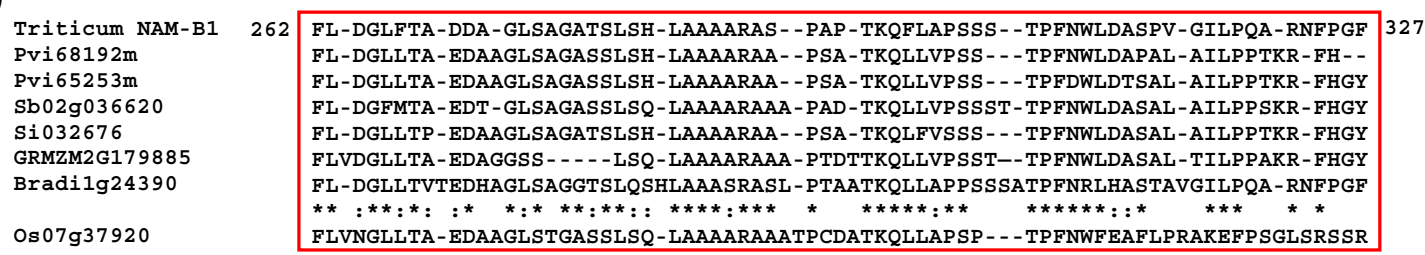

At1g61110 F-DGMVV--SSDKRSLCGQYRMGHEASGSSS

Pvi18572m FNDPSLAHFFEDGGVPDMARLDQHHHHQHGGATLLGHPVTSQLLINNGNSG

(b)

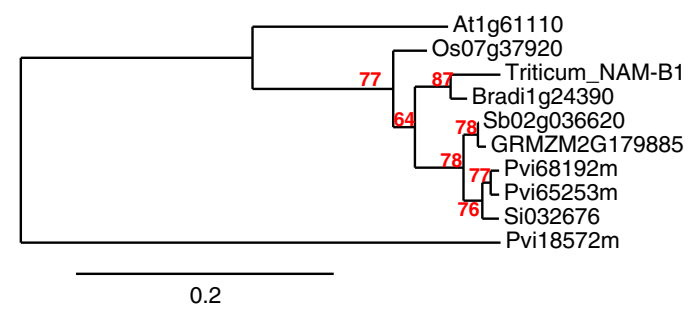

(c)

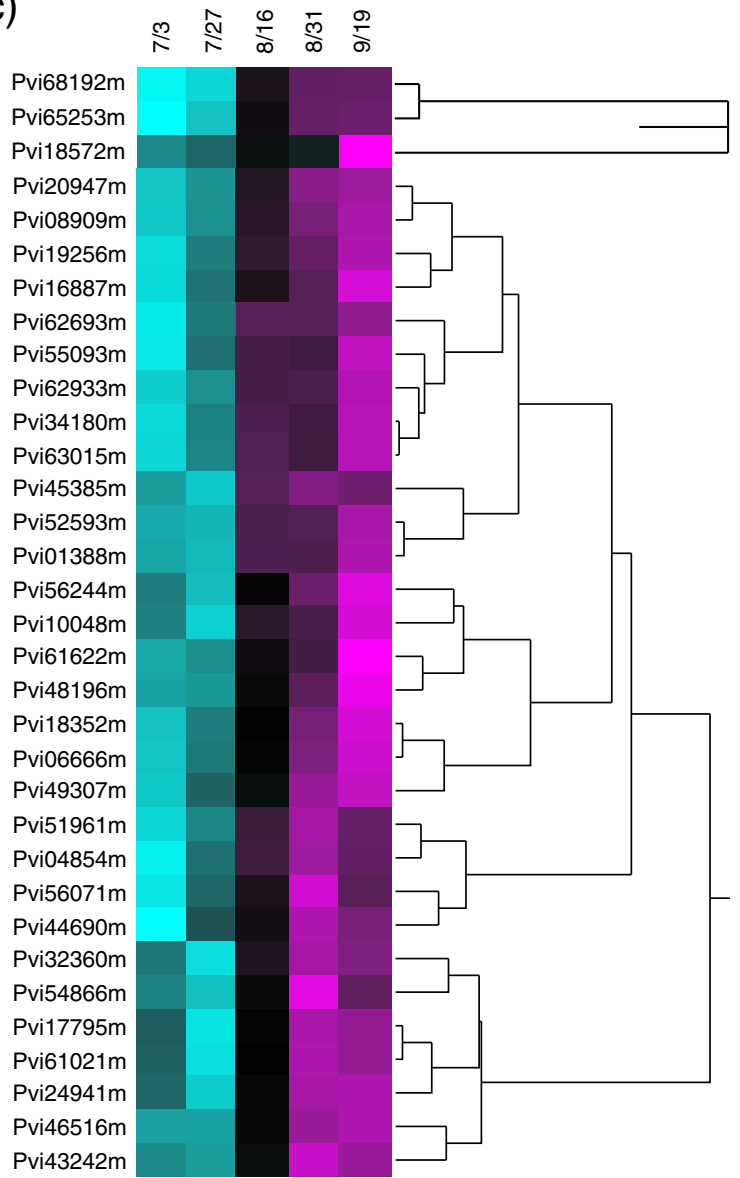

Expression profiles of switchgrass genes with high $(>0.9)$ correlation to the expression profiles of potential remobilization NACs shown in panel a. Gene identities are provided in supplementary file 1
Fig. 9 Identification of switchgrass NACs orthologous to Triticum dicoccoides NAM B1 and profiles of co-expressed genes. a The wheat NAM-B1 conserved domain is present in two switchgrass NAC genes (red box). b A dendrogram of the sequences used in this study. c

and Os07g37920 were more related to each other, compared to the other grass sequences analyzed.

All three switchgrass NACs described above (Fig. 9b) had an expression profile that linked them to the senescence process (Fig. 9c) akin to what has been demonstrated for wheat NAM-B1 (Waters et al. 2009). Transcriptional profiles of some select genes coexpressed with the NACs described above (with an expression correlation of $>0.9$ ) included the Mo transporters, several hydrolases, and other genes coding for NACs, autophagy, and catalase 2 proteins (Fig. 9c).

\section{Discussion}

To determine whether gene expression profiles in flag leaves collected at different times throughout development corresponded with known markers of leaf development, we tracked chlorophyll content as a known marker of leaf expansion and senescence onset (Hortensteiner and Krautler 2011; Thomas 2013). Chlorophyll content in flag leaves increased from the time of heading to the onset of seed set and declined thereafter, similar to patterns reported for flag leaves in cereal crops (Derkx et al. 2012; Kajimura et al. 2010; Liu et al. 
2008). Chlorophyll biosynthesis and degradation are catalyzed by a unique set of enzymes (Hortensteiner and Krautler 2011; Reinbothe et al. 2010), and the first molecular signature for the initiation of leaf senescence is the onset of expression of genes coding for chlorophyll breakdown (Hortensteiner and Krautler 2011). Consistent with these prior observations, transcript abundances were high for the genes coding for chlorophyll biosynthesis during the early part of switchgrass flag leaf development and declined thereafter; whereas, transcripts for genes coding for enzymes involved in chlorophyll degradation were significantly greater with the onset of leaf senescence. Overall, data on the transcript abundances for genes linked to $\mathrm{C}, \mathrm{N}$, and redox balance were consistent with published work on other plant species such as maize and rice (Erley et al. 2010; Liu et al. 2008; Sekhon et al. 2012) and the suggested roadmap for switchgrass flag leaf development (see Fig. 2).

Pathway analyses also supported these overall findings and indicated that a projected loss of cytokinin synthesis with the cessation of flag leaf growth and the up-regulation of targets of the transcription factor TT2 during the onset of senescence were as expected (Hoch et al. 2001; Riefler et al. 2006). A possible role for miRNA156 was also discerned through pathway analyses. MiRNA156 is a well-known positive regulator of flowering (Wang et al. 2009) and has also been implicated in regulation of senescence through downregulation of ORESARA 1 (Reinbothe et al. 2009). These findings were consistent with the floral development activity during phase 2 and senescence during phase 4 described in Fig. 2. As small RNAs, these signals have the additional possibility of being systemic regulators of development (Yoo et al. 2004) and might participate in the circuits that link shoot senescence to the onset of rhizome dormancy towards the end of the growing season (Sarath et al. 2014).

Although the early phases of flag leaf development are important to the efficient functioning of the leaf as a source of fixed carbon, the timing and onset of senescence are of considerable basic and applied interest (Sarath et al. 2014). In switchgrass, flag leaves appear to be functional after seeds have attained physiological maturity (this work), and thus could continue to serve as a source of photosynthate to the rhizomes towards the end of a growing season. Furthermore, it is likely that flag leaf senescence is intimately linked to the remobilization of nutrients from the shoots to the rhizomes contributing to the perenniality of the plant (Sarath et al. 2014).

Among the host of metabolic changes that occur during the onset of leaf senescence are increase in reactive oxygen species (ROS), the suppression of transcription of genes, and the remobilization of nutrients to sinks (Thomas 2013). Increase or decrease in transcripts of genes in these diverse pathways was discerned in switchgrass flag leaves, especially as they entered phase 4 (see Fig. 2) of development. As examples, genes coding for enzymes involved in $\mathrm{C}$ and $\mathrm{N}$ assimilation and ascorbate biosynthesis were down-regulated, and other genes implicated in alleviating oxidative stress and substrate level generation of $\mathrm{NAD}(\mathrm{P}) \mathrm{H}$, including several $S A G s$, were up-regulated.

Lowered levels of ascorbate and higher ROS have been associated with the progression of leaf senescence (Chen et al. 2013; Gallie 2013; Srivalli and Khanna-Chopra 2009), and increased abundance of isocitrate dehydrogenase (ICDH; Fig. 3) has been suggested to reduce oxidative stress by regenerating NADPH (Mhamdi et al. 2010). Substrate level regeneration of NADPH might be important in senescing switchgrass leaves when mitochondrial generation of reducing equivalents could become compromised. Several switchgrass SAGs with potential roles during leaf senescence were also identified. Among these, SAG14-HEXOKINASE-1 and SAG28-ATAF1 are known to be involved in different aspects of cellular signaling involving sugars (Hanson and Smeekens 2009; Pourtau et al. 2006) and signaling involving ROS (Wu et al. 2009) in other plants. $S A G$ 18, which codes for a cytosolic NADP-malic enzyme (NADP-ME), was also present in this cohort. NADP-ME is expected to provide NADPH and pyruvate in the cytoplasm. The expression profiles for the NADP-ME (SAG 2 and SAG18) mirrored those of the HEXOKINASE1 SAG14 (Fig. 7) suggesting that the transcriptional co-expression profiles of these genes could be linked to changes in the sugar, nitrogen, and redox metabolism expected with the onset and progression of leaf senescence (Thomas 2013). Sugar sensing has been proposed to be coupled to ROS through an interplay between the cytoplasm and mitochondria (Xiang et al. 2011), which in turn is linked to the production of ascorbate and ascorbate utilizing enzymes such as ascorbate peroxidases and other redox processes (Bolouri-Moghaddam et al. 2010; Xiang et al. 2011). SAG 57 and $S A G$ 63, which code for cytosolic ascorbate peroxidases, were significantly up-regulated during phase 4.

There were significant increases in transcript abundance for glutamate dehydrogenase (GDH, Fig. 3) over time. In Arabidopsis, GDH isoforms are largely localized in the mitochondria present in phloem companion cells in leaves and roots (Fontaine et al. 2012). They are also important to the catabolism and remobilization of amino acids during seed germination and senescence and are expected to be involved in signaling associated with $\mathrm{C}$ and $\mathrm{N}$ metabolism in plants (Forde and Lea 2007; Lehmann and Ratajczak 2008; Marchi et al. 2013). We also observed a significant up-regulation of genes involved in the remobilization of lipids with the onset of senescence primarily through the action of lipases and $\beta$ oxidation. It is known that lipids are lost from senescing switchgrass leaves (Yang and Ohlrogge 2009), and upregulation of genes coding for enzymes in the $\beta$-oxidation and a large number of lipases occurs in senescing Arabidopsis leaves (Troncoso-Ponce et al. 2013). However, 
gluconeogenesis did not appear to be occurring during leaf senescence in switchgrass, since transcripts for a key enzyme (PEPCK; Fig. 3) were low in senescing leaves and highest during the phases 1 and 2 of leaf development, in accordance to data from cucumber cotyledons and barley leaves (Chen et al. 2000b). Similar changes in the profiles for lipid degradation pathways have been reported in barley and sweet potato leaves (Chen et al. 2000a, 2000b). Our data also suggest that much of the organic acids are used as skeletons to synthesize amino acids (see Fig. 8), chiefly ASN, GLN, and possibly GLU, for eventual export to sinks, probably the rhizomes.

Epigenetic control of plant development is well established (Berr et al. 2011), and transcripts for a large number of switchgrass genes coding for these histone modifying enzymes were differentially regulated during flag leaf development. As examples, genes encoding switchgrass Jumonji-type demethylases $J M J 5$ and $J M J 6$ (Fig. 5) were most highly expressed in senescing leaves. Switchgrass JMJ6 is orthologous to the Arabidopsis PKDM7B (AT4G20400) gene that codes for an enzyme that demethylates histone $\mathrm{H} 3$ lysine 4 and suppresses gene transcription (Yang et al. 2010).

Mineral acquisition, transport, and remobilization is an integral part of plant development, and senescence often serves as a cue for redistribution of some, but not all, minerals from senescing tissues to sinks. Mineral concentration data from switchgrass crowns and rhizomes (Palmer et al. 2014) and aerial biomass (Wilson et al. 2013) harvested over the course of a growing season would indicate that there is remobilization of several minerals from the shoots to the rhizomes. Several genes coding for different classes of switchgrass mineral nutrient transporters were significantly overexpressed during the phase 2 (period of active growth) or during phase 4 (onset of senescence). These included transporters for ammonia (AMT), K (KUP), S (SULTR), P (PHO), and Zn (ZIP) (Fig. 6). These nutrients are needed during active growth and can be remobilized during senescence, (Abdallah et al. 2011; Nagarajan et al. 2011; Sinclair and Kramer 2012; Wang and Wu 2013), suggesting that these specific switchgrass genes are integral for efficient mineral mobilization.

There was a significant up-regulation in putative MOTs with the onset of leaf senescence. The switchgrass genome appears to code for at least five MOTs (Palmer et al. 2014). In plants, molybdenum is assimilated into a pterin to form the MoCo factor, which is present in nitrate reductase (NR), xanthine dehydrogenase (XDH), sulfite oxidase (SO), and aldehyde oxidase (AO) (Mendel and Kruse 2012). How Mo is remobilized during leaf senescence is not known. However, $\mathrm{XDH}$ appears to be important for scavenging purines into ureides during leaf senescence (Brychkova et al. 2008). Of four switchgrass genes predicted to code for $X D H$ (Pavirv00070280; Pavirv00060710; Pavirv00032623; Pavirv00030276), the first three exhibit increased transcript abundance during leaf senescence, in concert with the transcripts for three putative switchgrass ureide transporters (Pavirv00005720; Pavirv00055942; Pavirv00023499), suggestive of a role in moving ureides $(\mathrm{N}$ and $\mathrm{C}$ ) from senescing tissues to the crowns and rhizomes, as has been described for Arabidopsis (Brychkova et al. 2008). Changes in the flux of C and $\mathrm{N}$ metabolites could link aerial senescence to the onset of dormancy in the crowns and rhizomes, since these metabolites can serve as signals integrating physiological processes (Forde and Lea 2007; Zheng 2009). In Arabidopsis, there are two MOTS, and MOT2 protein is involved in molybdenum transport and allocation within the plant. Arabidopsis MOT2 transcripts have been documented to be elevated in senescent tissues (Gasber et al. 2011).

Plant developmental processes are controlled through the concerted action of transcription factors, and a number of these factors involved in senescence and affecting the remobilization of nutrients to sink tissues have been described (Ricachenevsky et al. 2013; Thomas 2013). Although a large number of switchgrass genes coding for transcription factor families were identified and shown to be divergently expressed (Fig. S3; Fig. 9), there were three NAC genes that were up-regulated close to the onset of senescence. Two of these three NACs were orthologous to the Wheat NAM-B1 shown to impact nutrient remobilization (Waters et al. 2009) suggesting a similar role in switchgrass. The third switchgrass NAC which lacks the C-terminal NAM-B1 signature domain (Fig. 9) appears to be orthologous to Arabidopsis NAC 029 (AT1G62300), which has a known role in promoting leaf senescence (Guo and Gan 2006), suggesting a similar role in switchgrass and reinforcing the evidence for NACs (Pavirv00068192 and Pavirv00065253) to be involved in nutrient remobilization from senescing flag leaves. Unlike switchgrass and wheat, the rice and Arabidopsis orthologs to Wheat $N A M-B 1$ were most abundantly expressed in anthers (Alvarado et al. 2011; Distelfeld et al. 2012), and the orthologous rice NAC did not have a role in nutrient remobilization (Distelfeld et al. 2012). These data would indicate that some caution is needed before fully ascribing the role of these three switchgrass NACs as causally related to remobilization and senescence. Nevertheless, the expression data for the switchgrass NACs discussed above support their role in flag leaf senescence. Among the genes that displayed a significant co-expression profile with the NACs were the MOTS (discussed above) and several $S A G S$, including genes coding for an autophagy protein and catalase. The autophagy ortholog in Arabidopsis (AT3G19190; ATG2) is involved in the early stages of the biogenesis of the autophagosomes (Wang et al. 2011), and lowered expression of the catalase 2 ortholog in Arabidopsis (AT4G35090, CATALASE2) leads to premature senescence (Smykowski et al. 2010). These data indicate that phase 4 switchgrass leaves were not fully senescent and required proteins such as CATALASE 2 to maintain 
cellular function and permit the remobilization of nutrients from the flag leaves to the rhizomes. Seeds were at physiological maturity at this harvest date, and unlikely to be active sinks, indicating a bulk of the remobilized nutrients was targeted to the belowground tissues.

Our data provide a comprehensive, global transcriptomic inspection of switchgrass flag leaf development. The coordination of gene expression with known physiological processes during leaf development provides new insights into biochemistry, mineral metabolism, and epigenetic processes. Because we have identified specific transcripts, our data can be mined for other insights and will inform future investigations. Overall, we identified several genes that could be important to signaling the onset of senescence and nutrient remobilization.

\begin{abstract}
Acknowledgments We thank Drs. James D. Eudy and Alok Dhar for sample preparation and analysis on the Illumina Hi-Seq 2,000 instrument. We thank Dr. Aaron J. Saathoff for help with leaf collection. This work was supported in part by the Office of Science (BER), US Department of Energy Grant Number DE-AI02-09ER64829, USDA-NIFA Grant Number 2011-67009-30096, and by the USDA-ARS CRIS project 544021000-030-00D. The US Department of Agriculture, Agricultural Research Service, is an equal opportunity/affirmative action employer and all agency services are available without discrimination. Mention of commercial products and organizations in this manuscript is solely to provide specific information. It does not constitute endorsement by USDA-ARS over other products and organizations not mentioned.

The University of Nebraska DNA Sequencing Core receives partial support from the NCRR (1S10RR027754-01, 5P20RR016469, RR018788-08) and the National Institute for General Medical Science (NIGMS) (8P20GM103427, GM103471-09). This publication's contents are the sole responsibility of the authors and do not necessarily represent the official views of the NIH or NIGMS.
\end{abstract}

\section{References}

Abdallah M, Etienne P, Ourry A, Meuriot F (2011) Do initial S reserves and mineral $\mathrm{S}$ availability alter leaf S-N mobilization and leaf senescence in oilseed rape? Plant Sci 180:511-520

Altschul SF, Gish W, Miller W, Myers EW, Lipman DJ (1990) Basic local alignment search tool. J Mol Biol 215:403-410. doi:10.1006/jmbi. 1990.9999 S0022283680799990 [pii]

Alvarado VY, Tag A, Thomas TL (2011) A cis regulatory element in the TAPNAC promoter directs tapetal gene expression. Plant Mol Biol 75:129-139. doi:10.1007/s11103-010-9713-5

Anders S, Huber W (2010) Differential expression analysis for sequence count data. Genome Biol 11(10):R106

Bartley L, Wu Y, Saathoff A, Sarath G (2013) Switchgrass genetics and breeding challenges. Wiley, New York, pp 7-31

Berr A, Shafiq S, Shen WH (2011) Histone modifications in transcriptional activation during plant development. Biochim Biophys Acta 1809:567-576. doi:10.1016/j.bbagrm.2011.07.001

Biswal AK, Kohli A (2013) Cereal flag leaf adaptations for grain yield under drought: knowledge status and gaps. Mol Breed 31:749-766

Bolouri-Moghaddam MR, Le Roy K, Xiang L, Rolland F, Van den Ende W, Van den Ende W (2010) Sugar signalling and antioxidant network connections in plant cells. FEBS J 277:2022-2037. doi:10. 1111/j.1742-4658.2010.07633.x
Brychkova G, Alikulov Z, Fluhr R, Sagi M (2008) A critical role for ureides in dark and senescence-induced purine remobilization is unmasked in the Atxdh1 Arabidopsis mutant. Plant J 54:496-509

Chen HJ, Hou WC, Jane WN, Lin YH (2000a) Isolation and characterization of an isocitrate lyase gene from senescent leaves of sweet potato (Ipomoea batatas cv. Tainong 57). J Plant Physiol 157:669676

Chen HJ, Huang CS, Huang GJ, Chow TJ, Lin YH (2013) NADPH oxidase inhibitor diphenyleneiodonium and reduced glutathione mitigate ethephon-mediated leaf senescence, $\mathrm{H}_{2} \mathrm{O}_{2}$ elevation and senescence-associated gene expression in sweet potato (Ipomoea batatas). J Plant Physiol 170:1471-1483. doi:10.1016/j.jplph. 2013.05.015

Chen ZH, Walker RP, Acheson RM, Tecsi LI, Wingler A, Lea PJ, Leegood RC (2000b) Are isocitrate lyase and phosphoenolpyruvate carboxykinase involved in gluconeogenesis during senescence of barley leaves and cucumber cotyledons? Plant Cell Physiol 41:960 967

Chollet R, Vidal J, O'Leary MH (1996) PHOSPHOENOLPYRUVATE CARBOXYLASE: a ubiquitous, highly regulated enzyme in plants annual review of plant physiology and plant molecular biology. Ann Rev Plant Physiol Plant Mol Biol 47:273-298. doi:10.1146/annurev. arplant.47.1.273

Cigliano RA, Sanseverino W, Cremona G, Ercolano MR, Conicella C, Consiglio FM (2013) Genome-wide analysis of histone modifiers in tomato: gaining an insight into their developmental roles. BMC Genomics 14:57

Davies PJ, Gan S (2012) Towards an integrated view of monocarpic plant senescence. Russ J Plant Phys1 59:467-478. doi:10.1134/ S102144371204005x

Derkx AP, Orford S, Griffiths S, Foulkes MJ, Hawkesford MJ (2012) Identification of differentially senescing mutants of wheat and impacts on yield, biomass and nitrogen partitioning. J Integr Plant Biol 54:555-566. doi:10.1111/j.1744-7909.2012.01144.x

Distelfeld A et al (2012) Divergent functions of orthologous NAC transcription factors in wheat and rice. Plant Mol Biol. doi:10.1007/ s11103-012-9881-6

Erley GSA, Ambebe TF, Worku M, Banziger M, Horst WJ (2010) Photosynthesis and leaf-nitrogen dynamics during leaf senescence of tropical maize cultivars in hydroponics in relation to $\mathrm{N}$ efficiency in the field. Plant Soil 330:313-328

Fontaine JX et al (2012) Characterization of a NADH-dependent glutamate dehydrogenase mutant of Arabidopsis demonstrates the key role of this enzyme in root carbon and nitrogen metabolism. Plant Cell 24:4044-4065. doi:10.1105/tpc.112.103689

Forde BG, Lea PJ (2007) Glutamate in plants: metabolism, regulation, and signalling. J Exp Bot 58:2339-2358

Gallie DR (2013) The role of L-ascorbic acid recycling in responding to environmental stress and in promoting plant growth. J Exp Bot 64: 433-443. doi:10.1093/jxb/ers330

Gasber A et al (2011) Identification of an Arabidopsis solute carrier critical for intracellular transport and inter-organ allocation of molybdate. Plant Biol (Stuttg) 13:710-718. doi:10.1111/j.1438-8677. 2011.00448.x

Gepstein S et al (2003) Large-scale identification of leaf senescenceassociated genes. Plant Journal 36:629-642. doi:10.1046/j.1365313X.2003.01908.X

Gill SS, Tuteja N (2010) Reactive oxygen species and antioxidant machinery in abiotic stress tolerance in crop plants. Plant Physiol Biochem 48:909-930. doi:10.1016/j.plaphy.2010.08.016

Goodstein DM et al (2012) Phytozome: a comparative platform for green plant genomics. Nucleic Acids Res 40:D1178-D1186. doi:10.1093/ $\mathrm{Nar} / \mathrm{Gkr} 944$

Gregersen PL, Holm PB (2007) Transcriptome analysis of senescence in the flag leaf of wheat (Triticum aestivum L.). Plant Biotechnol J 5: 192-206. doi:10.1111/j.1467-7652.2006.00232.x 
Guo Y, Gan S (2006) AtNAP, a NAC family transcription factor, has an important role in leaf senescence. Plant J 46:601-612. doi:10.1111/j. 1365-313X.2006.02723.X

Hanson J, Smeekens S (2009) Sugar perception and signaling - an update. Curr Opin Plant Biol 12:562-567

Hoch WA, Zeldin EL, McCown BH (2001) Physiological significance of anthocyanins during autumnal leaf senescence. Tree Physiol 21:1-8

Hortensteiner S, Krautler B (2011) Chlorophyll breakdown in higher plants. Biochim Biophys Acta 1807:977-988. doi:10.1016/j. bbabio.2010.12.007

Kajimura T, Mizuno N, Takumi S (2010) Utility of leaf senescenceassociated gene homologs as developmental markers in common wheat. Plant Physiol Biochem 48:851-859. doi:10.1016/j.plaphy. 2010.08.014

Kanehisa M, Goto S, Sato Y, Furumichi M, Tanabe M (2012) KEGG for integration and interpretation of large-scale molecular data sets. Nucleic Acids Res 40:D109-114. doi:10.1093/nar/gkr988

Kanehisa M, Goto S, Sato Y, Kawashima M, Furumichi M, Tanabe M (2014) Data, information, knowledge and principle: back to metabolism in KEGG. Nucleic Acids Res 42:D199-205

Kohl S et al (2012) A putative role for amino acid permeases in sinksource communication of barley tissues uncovered by RNA-seq. BMC Plant Biol 12:154

Langmead B, Salzberg SL (2012) Fast gapped-read alignment with bowtie 2. Nature methods 9:357-359. doi:10.1038/nmeth.1923

Lehmann T, Ratajczak L (2008) The pivotal role of glutamate dehydrogenase (GDH) in the mobilization of $\mathrm{N}$ and $\mathrm{C}$ from storage material to asparagine in germinating seeds of yellow lupine. J Plant Physiol 165:149-158

Li Z, Peng J, Wen X, Guo H (2012) Gene network analysis and functional studies of senescence-associated genes reveal novel regulators of Arabidopsis leaf senescence. J Integr Plant Biol. doi:10.1111/j. 1744-7909.2012.01136.x

Liao Y, Smyth GK, Shi W (2013) featureCounts: an efficient general purpose program for assigning sequence reads to genomic features. Bioinformatics 30(7):923-930. doi:10.1093/bioinformatics/btt656

Lim PO, Lee IC, Kim J, Kim HJ, Ryu JS, Woo HR, Nam HG (2010) Auxin response factor 2 (ARF2) plays a major role in regulating auxin-mediated leaf longevity. J Exp Bot 61:1419-1430

Linster CL, Clarke SG (2008) L-Ascorbate biosynthesis in higher plants: the role of VTC2. Trends Plant Sci 13:567-573. doi:10.1016/j. tplants.2008.08.005

Liu F, Chang XJ, Ye Y, Xie WB, Wu P, Lian XM (2011a) Comprehensive sequence and whole-life-cycle expression profile analysis of the phosphate transporter gene family in rice. Mol Plant 4:1105-1122. doi: $10.1093 / \mathrm{mp} / \mathrm{ssr} 058$

Liu L, Zhou Y, Zhou G, Ye R, Zhao L, Li X, Lin Y (2008) Identification of early senescence-associated genes in rice flag leaves. Plant Mol Biol 67:37-55

Liu X et al (2011b) LSD: a leaf senescence database. Nucleic Acids Res 39:D1103-1107. doi:10.1093/nar/gkq1169

Lu F, Cui X, Zhang S, Jenuwein T, Cao X (2011) Arabidopsis REF6 is a histone H3 lysine 27 demethylase. Nat Genet 43:715-719

Marchi L, Degola F, Polverini E, Terce-Laforgue T, Dubois F, Hirel B, Restivo FM (2013) Glutamate dehydrogenase isoenzyme 3 (GDH3) of Arabidopsis thaliana is regulated by a combined effect of nitrogen and cytokinin. Plant Physiol Biochem 73:368-374

Mendel RR, Kruse T (2012) Cell biology of molybdenum in plants and humans. Biochim Biophys Acta 1823:1568-1579. doi:10.1016/j. bbamcr.2012.02.007

Mhamdi A, Mauve C, Gouia H, Saindrenan P, Hodges M, Noctor G (2010) Cytosolic NADP-dependent isocitrate dehydrogenase contributes to redox homeostasis and the regulation of pathogen responses in Arabidopsis leaves. Plant Cell Environ 33:1112-1123. doi:10.1111/j.1365-3040.2010.02133.x
Mitchell RB, Moore KJ, Moser LE, Fritz JO, Redfearn DD (1997) Predicting developmental morphology in switchgrass and big bluestem. Agron J 89:827-832

Moore KJ, Moser LE (1995) Quantifying developmental morphology of perennial grasses. Crop Science 35:37-43

Nagarajan VK, Jain A, Poling MD, Lewis AJ, Raghothama KG, Smith AP (2011) Arabidopsis Pht 1;5 mobilizes phosphate between source and sink organs and Influences the interaction between phosphate homeostasis and ethylene signaling. Plant Physiol 156:1149-1163. doi:10.1104/pp.111.174805

Nikitin A, Egorov S, Daraselia N, Mazo I (2003) Pathway studio- the analysis and navigation of molecular networks. Bioinformatics 19: 2155-2157

Palmer NA et al (2012) Next-generation sequencing of crown and rhizome transcriptome from an upland, tetraploid switchgrass. Bioenergy Research 5:649-661

Palmer NA et al (2014) Global changes in mineral transporters in tetraploid switchgrasses (Panicum virgatum L.). Frontiers in plant science 4:549. doi:10.3389/fpls.2013.00549

Patwardhan PR, Satrio JA, Brown RC, Shanks BH (2010) Influence of inorganic salts on the primary pyrolysis products of cellulose. Bioresour Technol 101:4646-4655. doi:10.1016/j.biortech.2010.01.112

Perez-Rodriguez P, Riano-Pachon DM, Correa LG, Rensing SA, Kersten B, Mueller-Roeber B (2010) PlnTFDB: updated content and new features of the plant transcription factor database. Nucleic Acids Res 38:D822-827. doi:10.1093/nar/gkp805

Porra RJ, Thompson WA, Kriedemann PE (1989) Determination of accurate extinction coefficients and simultaneous-equations for assaying chlorophyll-a and chlorophyll-b extracted with 4 different solvents - verification of the concentration of chlorophyll standards by atomic-absorption spectroscopy. Biochimica Et Biophysica Acta 975:384-394

Pourtau N, Jennings R, Pelzer E, Pallas J, Wingler A (2006) Effect of sugar-induced senescence on gene expression and implications for the regulation of senescence in Arabidopsis. Planta 224:556-568

Puranik S, Sahu PP, Srivastava PS, Prasad M (2012) NAC proteins: regulation and role in stress tolerance. Trends Plant Sci 17:369-381

Rauf M et al (2013) ORE1 balances leaf senescence against maintenance by antagonizing G2-like-mediated transcription. EMBO Reports 14: 382-388. doi:10.1038/embor.2013.24

Reinbothe C et al (2010) Chlorophyll biosynthesis: spotlight on protochlorophyllide reduction. Trends in Plant Science 15:614-624

Reinbothe C, Springer A, Samol I, Reinbothe S (2009) Plant oxylipins: role of jasmonic acid during programmed cell death, defence and leaf senescence. Febs J 276:4666-4681

Ricachenevsky FK, Menguer PK, Sperotto RA (2013) kNACking on heaven's door: how important are NAC transcription factors for leaf senescence and $\mathrm{Fe} / \mathrm{Zn}$ remobilization to seeds? Frontiers in Plant Science 4:226. doi:10.3389/fpls.2013.00226

Riefler M, Novak O, Strnad M, Schmulling T (2006) Arabidopsis cytokinin receptor mutants reveal functions in shoot growth, leaf senescence, seed size, germination, root development, and cytokinin metabolism. Plant Cell 18:40-54

Sarath G, Baird LM, Mitchell RB (2014) Senescence, dormancy and tillering in perennial C4 grasses. Plant Sci 217-218:140-151. doi: 10.1016/j.plantsci.2013.12.012

Sekhon RS, Childs KL, Santoro N, Foster CE, Buell CR, de Leon N, Kaeppler SM (2012) Transcriptional and metabolic analysis of senescence induced by preventing pollination in maize. Plant physiology 159:1730-1744. doi:10.1104/pp.112.199224

Sinclair SA, Kramer U (2012) The zinc homeostasis network of land plants. Biochim Biophys Acta 1823:1553-1567. doi:10.1016/j. bbamcr.2012.05.016

Smykowski A, Zimmermann P, Zentgraf U (2010) G-Box binding factor1 reduces CATALASE2 expression and regulates the onset of leaf senescence in Arabidopsis. Plant Physiol 153:1321-1331 
Srivalli S, Khanna-Chopra R (2009) Delayed wheat flag leaf senescence due to removal of spikelets is associated with increased activities of leaf antioxidant enzymes, reduced glutathione/oxidized glutathione ratio and oxidative damage to mitochondrial proteins. Plant Physiol Biochem 47:663-670

Team RC (2011) R: a language and environment for statistical computing. Vienna, Austria: R Foundation for Statistical Computing; 2012 Open access available at: http://cran r-project org

Thomas H (2013) Senescence, ageing and death of the whole plant. New Phytol 197:696-711

Thomas H, Thomas HM, Ougham H (2000) Annuality, perenniality and cell death. J Exp Bot 51:1781-1788

Troncoso-Ponce MA, Cao X, Yang Z, Ohlrogge JB (2013) Lipid turnover during senescence. Plant Sci 205-206:13-19. doi:10.1016/j. plantsci.2013.01.004

Vogel KP, Mitchell KB (2008) Heterosis in switchgrass: biomass yield in swards. Crop Science 48:2159-2164. doi:10.2135/cropsci2008.02. 0117

Vogel KP, Sarath G, Saathoff AJ, Mitchell RB (2011) Switchgrass Rsc. Energy Environ 3:341-380

Wang JW, Czech B, Weigel D (2009) miR156-regulated SPL transcription factors define an endogenous flowering pathway in Arabidopsis thaliana. Cell 138:738-749

Wang Y, Nishimura MT, Zhao T, Tang D (2011) ATG2, an autophagy-related protein, negatively affects powdery mildew resistance and mildew-induced cell death in Arabidopsis. Plant J 68:74-87

Wang Y, Wu WH (2013) Potassium transport and signaling in higher plants. Annu Rev Plant Biol. doi:10.1146/annurev-arplant-050312120153
Waters BM, Uauy C, Dubcovsky J, Grusak MA (2009) Wheat (Triticum aestivum) NAM proteins regulate the translocation of iron, zinc, and nitrogen compounds from vegetative tissues to grain. J Exp Bot 60: 4263-4274

Wayman S, Bowden R, Mitchell R (2013) Seasonal changes in shoot and root nitrogen distribution in switchgrass (Panicum virgatum). Bioenergy Research 7(1):243-252. doi:10.1007/s12155-013-9365-9

Wilson DM, Dalluge DL, Rover M, Heaton EA, Brown RC (2013) Crop management impacts biofuel quality: influence of switchgrass harvest time on yield, nitrogen and ash of fast pyrolysis products. Bioenergy Research 6:103-113

Wu Y et al (2009) Dual function of Arabidopsis ATAF1 in abiotic and biotic stress responses. Cell Res 19:1279-1290

Xiang L, Li Y, Rolland F, Van den Ende W (2011) Neutral invertase, hexokinase and mitochondrial ROS homeostasis: emerging links between sugar metabolism, sugar signaling and ascorbate synthesis. Plant Signal Behav 6:1567-1573

Yang J, Worley E, Wang M, Lahner B, Salt D, Saha M, Udvardi M (2009) Natural variation for nutrient use and remobilization efficiencies in switchgrass. Bioenergy Research 2:257-266

Yang W, Jiang D, Jiang J, He Y (2010) A plant-specific histone H3 lysine 4 demethylase represses the floral transition in Arabidopsis. Plant J 62:663-673

Yang Z, Ohlrogge JB (2009) Turnover of fatty acids during natural senescence of Arabidopsis, Brachypodium, and switchgrass and in Arabidopsis beta-oxidation mutants. Plant Physiol 150:1981-1989

Yoo BC et al (2004) A systemic small RNA signaling system in plants. Plant Cell 16:1979-2000

Zheng ZL (2009) Carbon and nitrogen nutrient balance signaling in plants. Plant Signal Behav 4:584-591 